\title{
Pid Controller with Roll Moment Rejection for Pneumatically Actuated Active Roll Control (Arc) Suspension System
}

\author{
Khisbullah Hudha1), Fauzi Ahmad1), Zulkiffli Abd. Kadir2) \\ and Hishamuddin Jamaluddin ${ }^{3}$ \\ 1)Vehicle Control and Biomechanics Research Group \\ for Vehicle Research and Development (CeVReD) \\ Universiti Teknikal Malaysia Melaka (UTeM) \\ Hang Tuah Jaya, 76100 Durian Tunggal Melaka. \\ E-mail1):khisbullah@utem.edu.my \\ E-mail1):fauzi.ahmad@utem.edu.my \\ ${ }^{2)}$ Dept. of Mech. Eng., Faculty of Engineering \\ Universiti Pertahanan Nasional Malaysia (UPNM) \\ Kem Sungai Besi, 57000 Kuala Lumpur, Malaysia \\ E-mail2): zulkiffli@upnm.edu.my \\ 3) Faculty of Mechanical Engineering \\ Universiti Teknologi Malaysia (UTM) \\ 81310 UTM Skudai, Johor, Malaysia \\ Email: hishamj@fkm.utm.my
}

\begin{abstract}
This chapter presents a successful implementation of PID controller for a pneumatically actuated active roll control suspension system in both simulation and experimental studies. For the simulation model, a full vehicle model which consists of ride, handling and tire subsystems to study vehicle dynamics behavior in lateral direction is derived. The full vehicle model is then validated experimentally using an instrumented experimental vehicle based on the driver input from the steering wheel. Two types of vehicle dynamics test are performed for the purpose of model validation namely step steer test and double lane change test. The results of model validation show that the behaviors of the model closely follow the behavior of a real vehicle with acceptable error. An active roll control (ARC) suspension system is then developed on the validated full vehicle model to reduce unwanted vehicle motions during cornering maneuvers such as body roll angle, body roll rate, vertical acceleration of the body and body heave. The proposed controller structure for the ARC system is PID control with roll moment rejection loop. The ARC system is then implemented on an instrumented experimental vehicle in which four units of pneumatic actuators are installed in parallel arrangement with the passive suspension system. The
\end{abstract}


results of the study shows that the proposed control structure is able to significantly improve the dynamics performance of the vehicle during step steer and double lane change maneuvers compared to a passive vehicle system. It can also be noted that the additional roll moment rejection loop is able to further improve the performance of the PID controller for the ARC system.

\section{Introduction}

PID controller is the most popular feedback controller used in the process industries. The algorithm is simple but it can provide excellent control performance despite variation in the dynamic characteristics of a process plant. PID controller is a controller that includes three elements namely proportional, integral and derivative actions. The PID controller was first placed on the market in 1939 and has remained the most widely used controller in process control until today (Araki, 2006). A survey performed in 1989 in Japan indicated that more than $90 \%$ of the controllers used in process industries are PID controllers and advanced versions of the PID controller (Takatsu et al., 1998).

The use of electronic control systems in modern vehicles has increased rapidly and in recent years, electronic ontrol systems can be easily found inside vehicles, where they are responsible for smooth ride, cruise control, traction control, anti-lock braking, fuel delivery and ignition timing. The successful implementation of PID controller for automotive systems have been widely reported in the literatures such as for engine control (Ying et al., 1999; Yuanyuan et al., 2008; Bustamante et al., 2000), vehicle air conditioning control (Zhang et al., 2010), clutch control (Wu et al., 2008; Wang et al., 2001 ), brake control (Sugisaka et al., 2006; Hashemi-Dehkordi et al., 2009; Zhang et al., 1999), active steering control (Marino et al., 2009; Yan et al., 2008), power steering control (Morita et al., 2008), drive train control (Mingzhu et al., 2008; Wei et al., 2010; Xu, et al., 2007), throttle control (Shoubo et al., 2009; Tan et al., 1999; Corno et al., 2008) and suspension control (Ahmad et al., 2008; Ahmad et al., 2009a; Ahmad et al., 2009b; Hanafi, 2010; Ayat et al., 2002a ).

Over the last two decades, various active chassis control systems for automotive vehicles have been developed and put to commercial utilization. In particular, Vehicle Dynamics Control (VDC) and Electronic Stability Program (ESP) systems have become very active and attracting research efforts from both academic community and automotive industries (Mammar and Koenig, 2002; McCann, 2000; Mokhiamar and Abe, 2002; Wang and Longoria, 2006). The main goals of active chassis control include improvement in vehicle stability, maneuverability and passenger comfort especially in adverse driving conditions.

Ignited by advanced electronic technology, many different active chassis control systems have been developed, such as traction control system (Borrelli et al., 2006), active steering control (Falcone et al., 2007), antilock braking system (Cabrera et al., 2005), active roll control suspension system and others. This study is part of the continuous efforts in the prototype development of a pneumatically actuated active roll control suspension system for passenger vehicles. The proposed ARC system is used to minimize the effects of unwanted roll and vertical body motions of the vehicle in the presence of steering wheel input from the driver. 
ARC system is a class of electronically controlled active suspension system. Although active suspension has been widely studied for decades, most of the research are focused on vehicle ride comfort, with only few papers (Williams and Haddad, 1995; Ayat et al., 2002a; Wang et al., 2005, Ayat et al., 2002b) studying how an active suspension system can improve vehicle handling. It is well-known that a vehicle tends to roll on its longitudinal axis if the vehicle is subjected to steering wheel input due to the weight transfer from the inside to the outside wheels. Some control strategies for ARC systems have been proposed to cancel out lateral weight transfer using active force control strategy (Hudha et al. 2003), hybrid fuzzy-PID (Xinpeng and Duan, 2007), speed dependent gain scheduling control (Darling and RossMartin, 1997), roll angle and roll moment control (Miege and Cebon, 2002), state feedback controller optimized with genetic algorithm (Du and Dong, 2007) and the combination of yaw rate and side slip angle feedback control (Sorniotti and D' Alfio, 2007).

In this study, ARC system is developed using four units of pneumatic system installed between lower arms and vehicle body. The proposed control strategy for the ARC system is the combination of PID based feedback control and roll moment rejection based feed forward control. Feedback control is used to minimize unwanted body heave and body roll motions, while the feed forward control is intended to reduce the unwanted weight transfer during steering input maneuvers. The forces produced by the proposed control structure are used as the target forces by the four unit of pneumatic system.

The use of pneumatic actuator for an active roll control suspension system is a relatively new concept and has not been thoroughly explored. The use of pneumatic system is rare in active suspension application although they have several advantages compared with other actuation systems such as hydraulic system. The main advantage of pneumatic system is their power-to-weight ratio which is better than hydraulic system. They are also clean, simple system and comparatively low cost (Smaoui et al., 2006). The disadvantage of pneumatic system is the unwanted nonlinearity because of the compressibility and springing effects of air (Situm et al., 2005; Richer and Hurmuzlu, 2000). Due to these difficulties, early use of pneumatic actuators was limited to simple applications that required only positioning at the two ends of the stroke. But, during the past decade, many researchers have proposed various approaches to continuously control the pneumatic actuators (Ben-Dov and Salcudean, 1995; Wang et al., 1999; Messina et al., 2005). It is shown that the comparative advantages and difficulties of pneumatic system are still interesting and also a challenging problems in controller design in order to achieve reasonable performance in terms of position and force controls.

The proposed control strategy is optimized for a 14 degrees of freedom (DOF) full vehicle model. The full vehicle model consists of 7-DOF vehicle ride model and 7-DOF vehicle handling model coupled with Calspan tyre model. The full vehicle model can be used to study the behavior of vehicle in lateral, longitudinal and vertical directions due to both road and driver inputs. Calspan tire model is employed due to its capability to predict the behavior of a real tire better than Dugoff and Magic formula tire model (Kadir et al., 2008).

Beside the proposed control structure, another consideration of this chapter is that the proposed control structure for the ARC system is implemented on a validated full vehicle 
model as well as on a real vehicle. It is common that the controllers, developed on the validated model, are ready to be implemented in practice with high level of confidence and need less fine tuning works. For the purpose of vehicle model validation, an instrumented experimental vehicle has been developed using a Malaysia National Car. Two types of road test namely step steer and double lane change test were performed using the instrumented experimental vehicle. The data obtained from the road tests are used as the validation benchmarks of the 14-DOF full vehicle model.

This chapter is organized as follows: The first section contains introduction and the review of some related works, followed by mathematical derivations of the 14-DOF full vehicle model with Calspan tyre model in the second section. The third section introduces the proposed controller structure for the ARC system. The fourth section presents the results of validation of the full vehicle model. Furthermore, improvements of vehicle dynamics performance on simulation studies and experimental tests using the proposed ARC system are presented in the fifth and the sixth section, respectively. The last section contains some conclusions.

\section{Full Vehicle Modeling with Calspan Tire Model}

The full-vehicle model of the passenger vehicle considered in this study consists of a single sprung mass (vehicle body) connected to four unsprung masses and is represented as a 14DOF system as shown in Figure 1. The sprung mass is represented as a plane and is allowed to pitch, roll and yaw as well as to displace in vertical, lateral and longitudinal directions. The unsprung masses are allowed to bounce vertically with respect to the sprung mass. Each wheel is also allowed to rotate along its axis and only the two front wheels are free to steer.

\subsection{Modeling Assumptions}

Some of the modeling assumptions considered in this study are as follows: the vehicle body is lumped into a single mass which is referred to as the sprung mass, aerodynamic drag force is ignored, and the roll centre is coincident with the pitch centre and located just below the body center of gravity. The suspensions between the sprung mass and unsprung masses are modeled as passive viscous dampers and spring elements. Rolling resistance due to passive stabilizer bar and body flexibility are neglected. The vehicle remains grounded at all times and the four tires never lost contact with the ground during maneuvering. A 4 degrees tilt angle of the suspension system toward vertical axis is neglected $(\cos 4=0.998 \approx 1)$. Tire vertical behavior is represented as a linear spring without damping, while the lateral and longitudinal behaviors are represented with Calspan model. Steering system is modeled as a constant ratio and the effect of steering inertia is neglected.

\subsection{Vehicle Ride Model}

The vehicle ride model is represented as a 7-DOF system. It consists of a single sprung mass (car body) connected to four unsprung masses (front-left, front-right, rear-left and rear-right wheels) at each corner of the vehicle body. The sprung mass is free to heave, pitch and roll while the unsprung masses are free to bounce vertically with respect to the sprung mass. 
The suspensions between the sprung mass and unsprung masses are modeled as passive viscous dampers and spring elements. While, the tires are modeled as simple linear springs without damping. For simplicity, all pitch and roll angles are assumed to be small. A similar model was used by Ikenaga (2000).

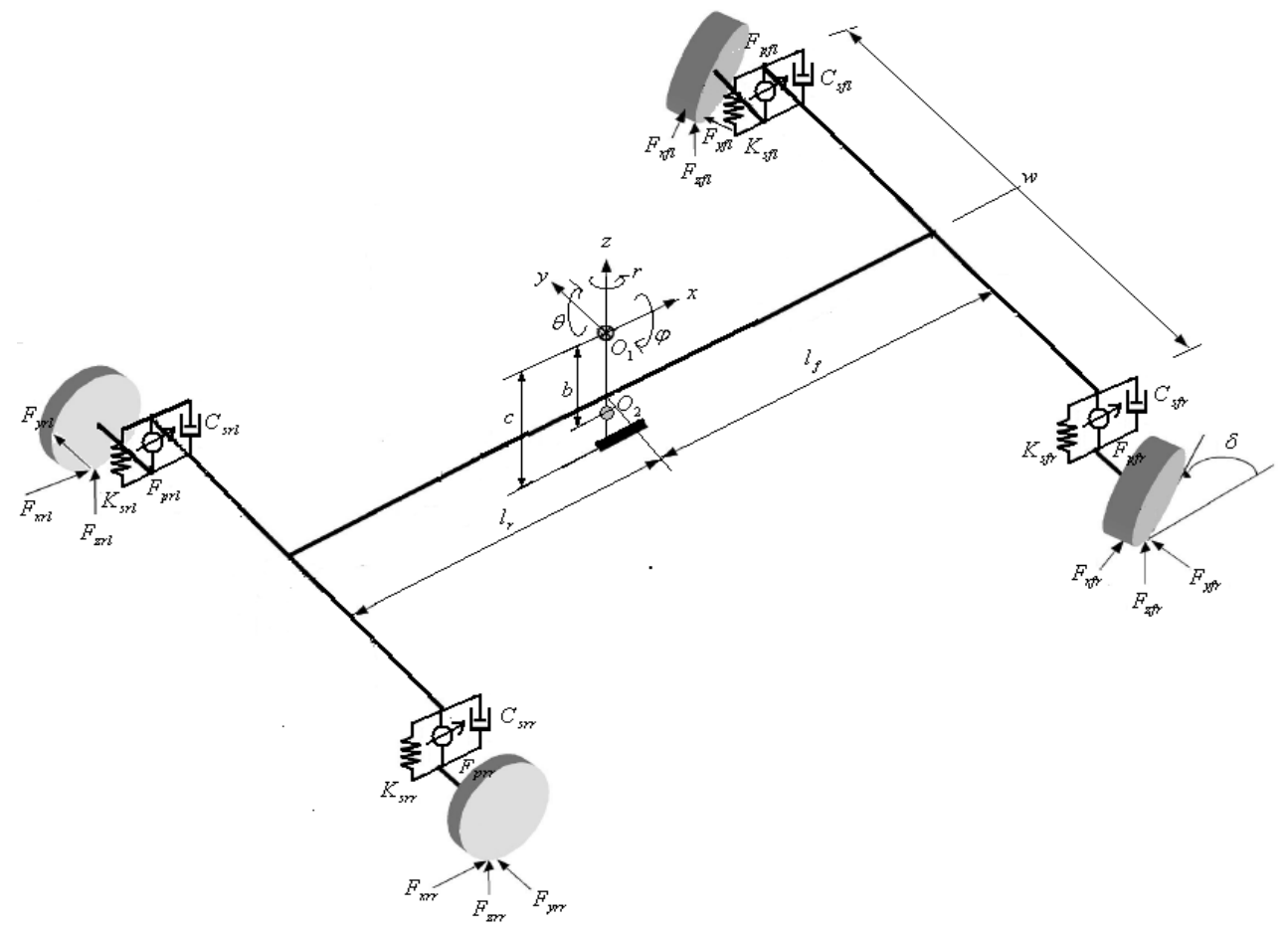

Fig. 1. A 14-DOF full vehicle ride and handling model

Referring to Figure 1, the force balance on sprung mass is given as

$$
F_{f l}+F_{f r}+F_{r l}+F_{r r}+F_{p f l}+F_{p f r}+F_{p r l}+F_{p r r}=m_{s} \ddot{Z}_{s}
$$

where,

$$
\begin{array}{ll}
F_{f l} & =\text { suspension force at front left corner } \\
F_{f r} & =\text { suspension force at front right corner } \\
F_{r l} & =\text { suspension force at rear left corner } \\
F_{r r} & =\text { suspension force at rear right corner } \\
m_{S} & =\text { sprung mass weight } \\
\ddot{Z}_{S} & =\text { sprung mass acceleration at body centre of gravity }
\end{array}
$$

$F_{p f l} ; F_{p f r} ; F_{p r l} ; F_{p r r}=$ pneumatic actuator forces at front left, front right, rear left and rear right corners, respectively. 
The suspension force at each corner of the vehicle is defined as the sum of the forces produced by suspension components namely spring force and damper force as the followings

$$
\begin{aligned}
& F_{f l}=K_{s, f l}\left(Z_{u, f l}-Z_{s, f l}\right)+C_{s, f l}\left(\dot{Z}_{u, f l}-\dot{Z}_{s, f l}\right) \\
& F_{f r}=K_{s, f r}\left(Z_{u, f r}-Z_{s, f r}\right)+C_{s, f r}\left(\dot{Z}_{u, f r}-\dot{Z}_{s, f r}\right) \\
& F_{r l}=K_{s, r l}\left(Z_{u, r l}-Z_{s, r l}\right)+C_{s, r l}\left(\dot{Z}_{u, r l}-\dot{Z}_{s, r l}\right) \\
& F_{r r}=K_{s, r r}\left(Z_{u, r r}-Z_{s, r r}\right)+C_{s, r r}\left(\dot{Z}_{u, r r}-\dot{Z}_{s, r r}\right)
\end{aligned}
$$

where,

$$
\begin{array}{ll}
K_{s, f l} & =\text { front left suspension spring stiffness } \\
K_{s, f r} & =\text { front right suspension spring stiffness } \\
K_{s, r r} & =\text { rear right suspension spring stiffness } \\
K_{s, r l} & =\text { rear left suspension spring stiffness } \\
C_{s, f r} & =\text { front right suspension damping } \\
C_{s, f l} & =\text { front left suspension damping } \\
C_{s, r r} & =\text { rear right suspension damping } \\
C_{s, r l} & =\text { rear left suspension damping } \\
Z_{u, f r} & =\text { front right unsprung mass displacement } \\
Z_{u, f l} & =\text { front left unsprung mass displacement } \\
Z_{u, r r} & =\text { rear right unsprung mass displacement } \\
Z_{u, r l} & =\text { rear left unsprung mass displacement } \\
\dot{Z}_{u, f r} & =\text { front right unsprung mass velocity } \\
\dot{Z}_{u, f l} & =\text { front left unsprung mass velocity } \\
\dot{Z}_{u, r r} & =\text { rear right unsprung mass velocity } \\
\dot{Z}_{u, r l} & =\text { rear left unsprung mass velocity }
\end{array}
$$

The sprung mass position at each corner can be expressed in terms of bounce, pitch and roll given by

$$
\begin{aligned}
& Z_{s, f l}=Z_{s}-l_{f} \sin \theta+0.5 w \sin \varphi \\
& Z_{s, f r}=Z_{s}-l_{f} \sin \theta-0.5 w \sin \varphi \\
& Z_{s, r l}=Z_{s}+l_{r} \sin \theta+0.5 w \sin \varphi \\
& Z_{s, r r}=Z_{s}+l_{r} \sin \theta-0.5 w \sin \varphi
\end{aligned}
$$


It is assumed that all angles are small, therefore Eq. (3) becomes

$$
\begin{aligned}
& Z_{s, f l}=Z_{s}-l_{f} \theta+0.5 w \varphi \\
& Z_{s, f r}=Z_{s}-l_{f} \theta-0.5 w \varphi \\
& Z_{s, r l}=Z_{s}+l_{r} \theta+0.5 w \varphi \\
& Z_{s, r r}=Z_{s}+l_{r} \theta-0.5 w \varphi
\end{aligned}
$$

where,

$$
\begin{array}{ll}
l_{f} & =\text { distance between front of vehicle and center of gravity of sprung mass } \\
l_{r} & =\text { distance between rear of vehicle and center of gravity of sprung mass } \\
w & =\text { track width } \\
\theta & =\text { pitch angle at body centre of gravity } \\
\varphi & =\text { roll angle at body centre of gravity } \\
Z_{s, f l} & =\text { front left sprung mass displacement } \\
Z_{s, f r} & =\text { front right sprung mass displacement } \\
Z_{s, r l} & =\text { rear left sprung mass displacement } \\
Z_{s, r r} & =\text { rear right sprung mass displacement }
\end{array}
$$

By substituting Eq. (4) and its derivative (sprung mass velocity at each corner) into Eq. (2) and the resulting equations are then substituted into Eq. (1), the following equation is obtained

$$
\begin{aligned}
m_{S} \ddot{Z}_{s}= & -2\left(K_{s, f}+K_{s, r}\right) Z_{s}-2\left(C_{s, f}+C_{s, r}\right) \dot{Z}_{s}+2\left(l_{f} K_{s, f}-l_{r} C_{s, r}\right) \theta \\
+ & 2\left(l_{f} C_{s, f}-l_{r} C_{s, r}\right) \dot{\theta}+K_{s f} Z_{u, f l}+C_{s, f} \dot{Z}_{u, f l}+K_{s f} Z_{u, f r}+ \\
& +C_{s, f} \dot{Z}_{u, f r} K_{s r} Z_{u, r l}+C_{s, r} \dot{Z}_{u, r l}+K_{s r} Z_{u, r r}+C_{s, r} \dot{Z}_{u, r r} \\
& +F_{p f l}+F_{p f r}+F_{p r l}+F_{p r r}
\end{aligned}
$$

where,
$\dot{\theta} \quad=$ pitch rate at body centre of gravity
$Z_{s} \quad=$ sprung mass displacement at body centre of gravity
$\dot{Z}_{s} \quad$ = sprung mass velocity at body centre of gravity
$K_{s, f} \quad=$ spring stiffness of front suspension $\left(K_{s, f l}=K_{s, f r}\right)$
$K_{s, r} \quad=$ spring stiffness of rear suspension $\left(K_{s, r l}=K_{s, r r}\right)$
$C_{s, f}=C_{s, f l}=C_{s, f r}=$ damping constant of front suspension
$C_{s, r}=C_{s, r l}=C_{s, r r}=$ damping constant of rear suspension 
Similarly, moment balance equations are derived for pitch $\theta$ and roll $\varphi$, and are given as

$$
\begin{gathered}
I_{y y} \ddot{\theta}=2\left(l_{f} K_{s, f}-l_{r} K_{s, r}\right) Z_{s}+2\left(l_{f} C_{s, f}-l_{r} C_{s, r}\right) \dot{Z}_{s}-2\left(l_{f}{ }^{2} K_{s, f}+l_{r}{ }^{2} K_{s, r}\right) \\
-2\left(l_{f}{ }^{2} C_{s, f}+l_{r}{ }^{2} C_{s, r}\right) \dot{\theta}-l_{f} K_{s, f} Z_{u, f l}-l_{f} C_{s, f} \dot{Z}_{u, f l}-l_{f} K_{s, f} Z_{u, f r}+ \\
-l_{f} C_{s, f} \dot{Z}_{u, f r}+l_{r} K_{s, r} Z_{u, r l}+l_{r} C_{s, r} \dot{Z}_{u, r l}+l_{r} K_{s, r} Z_{u, r r}+l_{r} C_{s, r} \dot{Z}_{u, r r} \\
-\left(F_{p f l}+F_{p f r}\right) l_{f}+\left(F_{p r l}+F_{p r r}\right) l_{r} \\
I_{x x} \ddot{\varphi}=-0.5 w^{2}\left(K_{s, f}+K_{s, r}\right) \varphi-0.5 w^{2}\left(C_{s, f}+C_{s, r}\right) \dot{\varphi}+0.5 w K_{s, f} Z_{u, f l}+ \\
+0.5 w C_{s, f} \dot{Z}_{u, f l}-0.5 w K_{s, f} Z_{u, f r}-0.5 w C_{s, f} \dot{Z}_{u, f r}+ \\
+0.5 w K_{s, r} Z_{u, r l}+0.5 w C_{s, r} \dot{Z}_{u, r l}-0.5 w K_{s, r} Z_{u, r r}-0.5 w C_{s, r} \dot{Z}_{u, r r} \\
+\left(F_{p f l}+F_{p r l}\right) \frac{w}{2}-\left(F_{p f r}+F_{p r r}\right) \frac{w}{2}
\end{gathered}
$$

where,

$$
\begin{array}{ll}
\ddot{\theta} & =\text { pitch acceleration at body centre of gravity } \\
\ddot{\varphi} & =\text { roll acceleration at body centre of gravity } \\
I_{x x} & =\text { roll axis moment of inertia } \\
I_{y y} & =\text { pitch axis moment of inertia }
\end{array}
$$

By performing force balance analysis at the four wheels, the following equations are obtained

$$
\begin{gathered}
m_{u} \ddot{Z}_{u, f l}=K_{s, f} Z_{s}+C_{s, f} \dot{Z}_{s}-l_{f} K_{s, f} \theta-l_{f} C_{s, f} \dot{\theta}+0.5 w K_{s, f} \varphi+ \\
+0.5 w C_{s, f} \dot{\varphi}-\left(K_{s, f}+K_{t}\right) Z_{u, f l}-C_{s, f} \dot{Z}_{u, f l}+K_{t} Z_{r, f l}-F_{p f l} \\
m_{u} \ddot{Z}_{u, f r}=K_{s, f} Z_{s}+C_{s, f} \dot{Z}_{s}-l_{f} K_{s, f} \theta-l_{f} C_{s, f} \dot{\theta}-0.5 w K_{s, f} \varphi+ \\
-0.5 w C_{s, f} \dot{\varphi}-\left(K_{s, f}+K_{t}\right) Z_{u, f r}-C_{s, f} \dot{Z}_{u, f r}+K_{t} Z_{r, f r}-F_{p f r} \\
m_{u} \ddot{Z}_{u, r l}=K_{s, r} Z_{s}+C_{s, r} \dot{Z}_{s}+l_{r} K_{s, r} \theta+l_{r} C_{s, r} \dot{\theta}+0.5 w K_{s, r} \varphi+ \\
\quad+0.5 w C_{s, r} \dot{\varphi}-\left(K_{s, r}+K_{t}\right) Z_{u, r l}-C_{s, r} \dot{Z}_{u, r l}+K_{t} Z_{r, r l}-F_{p r l} \\
\ddot{Z}_{u, r r}=K_{s, r} Z_{s}+C_{s, r} \dot{Z}_{s}+l_{r} K_{s, r} \theta+l_{r} C_{s, r} \dot{\theta}-0.5 w K_{s, r} \varphi+ \\
-0.5 w C_{s, r} \dot{\varphi}-\left(K_{s, r}+K_{t}\right) Z_{u, r r}-C_{s, r} \dot{Z}_{u, r r}+K_{t} Z_{r, r r}-F_{p r r}
\end{gathered}
$$


where,

$$
\begin{array}{cl}
\ddot{Z}_{u, f r} & =\text { front right unsprung mass acceleration } \\
\ddot{Z}_{u, f l} & =\text { front left unsprung mass acceleration } \\
\ddot{Z}_{u, r r} & =\text { rear right unsprung mass acceleration } \\
\ddot{Z}_{u, r l} & =\text { rear left unsprung mass acceleration } \\
Z_{r, f r}= & Z_{r, f l}=Z_{r, r r}=Z_{r, r l}=\text { road profiles at front left, front right, rear right } \\
\text { and rear left tyres respectively }
\end{array}
$$

\subsection{Vehicle Handling Model}

The handling model employed in this paper is a 7-DOF system as shown in Figure 2. It takes into account three degrees of freedom for the vehicle body in lateral and longitudinal motions as well as yaw motion $(r)$ and one degree of freedom due to the rotational motion of each tire. In vehicle handling model, it is assumed that the vehicle is moving on a flat road. The vehicle experiences motion along the longitudinal $x$-axis and the lateral $y$-axis, and the angular motions of yaw around the vertical $z$-axis. The motion in the horizontal plane can be characterized by the longitudinal and lateral accelerations, denoted by $a_{x}$ and $a_{y}$ respectively, and the velocities in longitudinal and lateral direction, denoted by $v_{x}$ and $v_{y}$, respectively.
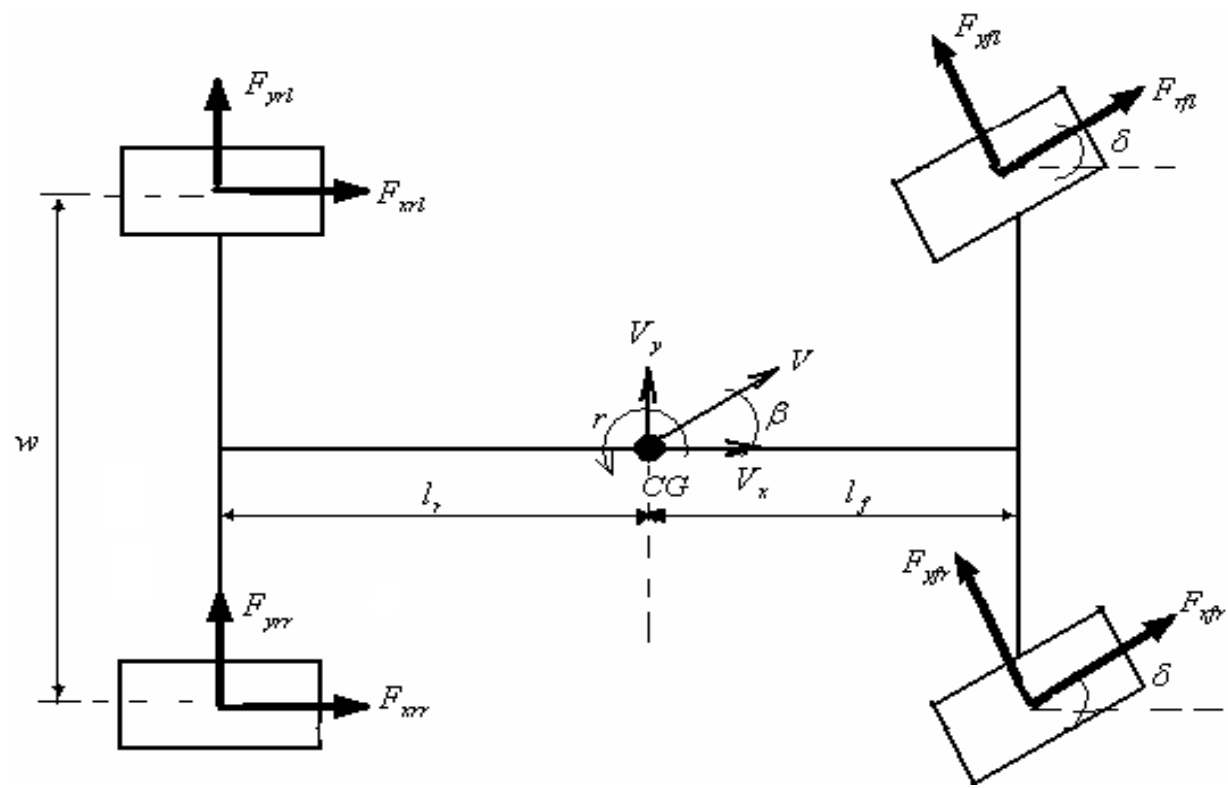

Fig. 2. A 7-DOF vehicle handling model 
Acceleration in longitudinal $x$-axis is defined as

$$
v_{x}=a_{x}+v_{y} r
$$

By summing all the forces in $x$-axis, longitudinal acceleration can be defined as

$$
a_{x}=\frac{F_{x f l} \cos \delta+F_{y f l} \sin \delta+F_{x f r} \cos \delta+F_{y f r} \sin \delta+F_{x r l}+F_{x r r}}{m_{t}}
$$

Similarly, acceleration in lateral $y$-axis is defined as

$$
\dot{v}_{y}=a_{y}-v_{x} \dot{r}
$$

By summing all the forces in lateral direction, lateral acceleration can be defined as

$$
a_{y}=\frac{F_{y f l} \cos \delta-F_{x f l} \sin \delta+F_{y f r} \cos \delta-F_{x f r} \sin \delta+F_{y r l}+F_{y r r}}{m_{t}}
$$

where $F_{x i j}$ and $F_{y i j}$ denote the tire forces in the longitudinal and lateral directions, respectively, with the index $(i)$ indicating front $(f)$ or rear $(r)$ tires and index $(j)$ indicating left (l) or right $(r)$ tires. The steering angle is denoted by $\delta$, the yaw rate by $\dot{r}$ and $m_{t}$ denotes the total vehicle mass. The longitudinal and lateral vehicle velocities $v_{x}$ and $v_{y}$ can be obtained by integrating of $v_{y}$ and $v_{x}$. They can be used to obtain the side slip angle, denoted by $a$. Thus, the slip angle of front and rear tires are found as

$$
\alpha_{f}=\tan ^{-1}\left(\frac{v_{y}+l_{f} r}{v_{x}}\right)-\delta_{f}
$$

and

$$
\alpha_{r}=\tan ^{-1}\left(\frac{v_{y}-l_{r} r}{v_{x}}\right)
$$

where, $\alpha_{f}$ and $\alpha_{r}$ are the side slip angles at front and rear tires respectively. While $l_{f}$ and $l_{r}$ are the distance between front and rear tire to the body center of gravity respectively. 
To calculate the longitudinal slip, longitudinal component of the tire velocity should be derived. The front and rear longitudinal velocity component is given by:

$$
v_{w x f}=V_{t f} \cos \alpha_{f}
$$

where, the speed of the front tire is,

$$
V_{t f}=\sqrt{\left(v_{y}+l_{f} r\right)^{2}+v_{x}^{2}}
$$

The rear longitudinal velocity component is,

$$
v_{w x r}=V_{t r} \cos \alpha_{r}
$$

where, the speed of the rear tire is,

$$
V_{t r}=\sqrt{\left(v_{y}+l_{r} r\right)^{2}+v_{x}^{2}}
$$

Then, the longitudinal slip ratio of front tire,

$$
S_{a f}=\frac{v_{w x f}-\omega_{f} R_{w}}{v_{w x f}}, \text { under braking conditions }
$$

The longitudinal slip ratio of rear tire is,

$$
S_{a r}=\frac{v_{w x r}-\omega_{r} R_{w}}{v_{w x r}}, \text { under braking conditions }
$$

where, $\omega_{r}$ and $\omega_{f}$ are angular velocities of rear and front tires, respectively and $R_{w}$, is the wheel radius. The yaw motion is also dependent on the tire forces $F_{x i j}$ and $F_{y i j}$ as well as on the self-aligning moments, denoted by $M_{z i j}$ acting on each tire:

$$
\begin{aligned}
\ddot{r}=\frac{1}{J_{z}}[ & \frac{w}{2} F_{x f l} \cos \delta-\frac{w}{2} F_{x f r} \cos \delta+\frac{w}{2} F_{x r l}-\frac{w}{2} F_{x r r}+\frac{w}{2} F_{y f l} \sin \delta- \\
& \frac{w}{2} F_{y f r} \sin \delta-l_{r} F_{y r l}-l_{r} F_{y r r}+l_{f} F_{y f l} \cos \delta+l_{f} F_{y f r} \cos \delta-l_{f} F_{x f l} \sin \delta- \\
& \left.l_{f} F_{x f r} \sin \delta+M_{z f l}+M_{z f r}+M_{z r l}+M_{z r r}\right]
\end{aligned}
$$


where, $J_{z}$ is the moment of inertia around the z-axis. The roll and pitch motion depend very much on the longitudinal and lateral accelerations. Since only the vehicle body undergoes roll and pitch, the sprung mass, denoted by $m_{s}$ has to be considered in determining the effects of handling on pitch and roll motions as the following:

$$
\begin{gathered}
\ddot{\varphi}=\frac{-m_{s} c a_{y}+\varphi\left(m_{s} g c-k_{\phi}\right)+\dot{\varphi}\left(-\beta_{\varphi}\right)}{J_{s x}} \\
\ddot{\theta}=\frac{-m_{s} c a_{y}+\theta\left(m_{s} g c-k_{\theta}\right)+\dot{\theta}\left(-\beta_{\theta}\right)}{J_{s y}}
\end{gathered}
$$

where, $c$ is the height of the sprung mass center of gravity from the ground, $g$ is the gravitational acceleration and $k_{\varphi}, \beta_{\varphi}, k_{\theta}$ and $\beta_{\theta}$ are the damping and stiffness constant for roll and pitch, respectively. The moments of inertia of the sprung mass around $x$-axis and $y$ axis are denoted by $J_{s x}$ and $J_{s y}$ respectively.

\subsection{Simplified Calspan Tire Model}

Tire model considered in this study is Calspan model as described in Szostak et al. (1988). Calspan model is able to describe the behavior of a vehicle in any driving scenario including inclement driving conditions which may require severe steering, braking, acceleration, and other driving related operations (Kadir et al., 2008). The longitudinal and lateral forces generated by a tire are a function of the slip angle and longitudinal slip of the tire relative to the road. The previous theoretical developments in Szostak et al. (1988) lead to a complex, highly non-linear composite force as a function of composite slip. It is convenient to define a saturation function, $f(\sigma)$, to obtain a composite force with any normal load and coefficient of friction values (Singh et al., 2000). The polynomial expression of the saturation function is presented by:

$$
f(\sigma)=\frac{F_{c}}{\mu F_{z}}=\frac{C_{1} \sigma^{3}+C_{2} \sigma^{2}+(4 / \pi) \sigma}{C_{1} \sigma^{3}+C_{2} \sigma^{2}+C_{4} \sigma+1}
$$

where, $C_{1}, C_{2}, C_{3}$ and $C_{4}$ are constant parameters fixed to the specific tires. The tire contact patch lengths are calculated using the following two equations:

$$
a p_{0}=\frac{0.0768 \sqrt{F_{z} F_{Z T}}}{T_{w}\left(T_{p}+5\right)}
$$




$$
a p=\left(1-\frac{K_{a} F_{x}}{F_{z}}\right)
$$

where $a p$ is the tire contact patch, $F_{z}$ is a normal force, $T_{w}$ is a tread width, and $T_{p}$ is a tire pressure. While $F_{Z T}$ and $K_{a}$ are tire contact patch constants. The lateral and longitudinal stiffness coefficients ( $K_{s}$ and $K_{c}$, respectively) are a function of tire contact patch length and normal load of the tire as expressed as follows:

$$
\begin{gathered}
K_{s}=\frac{2}{a p_{0}^{2}}\left(A_{0}+A_{1} F_{z}-\frac{A_{1} F_{z}^{2}}{A_{2}}\right) \\
K_{c}=\frac{2}{a p_{0}{ }^{2}} F_{z}(C S / F Z)
\end{gathered}
$$

where the values of $A_{0}, A_{1}, A_{2}$ and CS/FZ are stiffness constants. Then, the composite slip calculation becomes:

$$
\sigma=\frac{\pi a p^{2}}{8 \mu_{0} F_{z}} \sqrt{K_{s}{ }^{2} \tan ^{2} \alpha+K_{c}{ }^{2}\left(\frac{s}{1-s}\right)^{2}}
$$

Where $S$ is a tire longitudinal slip, $\alpha$ is a tire slip angle, and $\mu_{\mathrm{o}}$ is a nominal coefficient of friction and has a value of 0.85 for normal road conditions, 0.3 for wet road conditions, and 0.1 for icy road conditions. Given the polynomial saturation function, lateral and longitudinal stiffness, the normalized lateral and longitudinal forces are derived by resolving the composite force into the side slip angle and longitudinal slip ratio components:

$$
\begin{gathered}
\frac{F_{y}}{\mu F_{z}}=\frac{f(\sigma) K_{s} \tan \alpha}{\sqrt{K_{s}{ }^{2} \tan ^{2} \alpha+K_{c}^{\prime 2} S^{2}}}+Y_{\gamma} \gamma \\
\frac{F_{x}}{\mu F_{z}}=\frac{f(\sigma) K_{c}^{\prime} S}{\sqrt{K_{s}^{2} \tan ^{2} \alpha+K_{c}^{\prime 2} S^{2}}}
\end{gathered}
$$

Lateral force has an additional component due to the tire camber angle, $\gamma$, which is modeled as a linear effect. Under significant maneuvering conditions with large lateral and longitudinal slip, the force converges to a common sliding friction value. In order to meet 
this criterion, the longitudinal stiffness coefficient is modified at high slips to transition to lateral stiffness coefficient as well as the coefficient of friction defined by the parameter $K_{\mu}$.

$$
\begin{gathered}
K_{c}^{\prime}=K_{c}+\left(K_{s}-K_{c}\right) \sqrt{\sin ^{2} \alpha+S^{2} \cos ^{2} \alpha} \\
\mu=\mu_{0}\left(1-K_{\mu}\right) \sqrt{\sin ^{2} \alpha+S^{2} \cos ^{2} \alpha}
\end{gathered}
$$

\section{Controller Structure of Pneumatically Actuated Active Roll Control Suspension System}

The proposed controller structure consists of inner loop controller to reject the unwanted weight transfer and outer loop controller to stabilize heave and roll responses due to steering wheel input from the driver. An input decoupling transformation is placed between inner and outer loop controllers that blend the inner loop and outer loop controller. The outer loop controller provides the ride control that isolates the vehicle body from vertical and rotational vibrations induced by steering wheel input and the inner loop controller provides the weight transfer rejection control that maintains load-leveling and load distribution during vehicle maneuvers. The proposed control structure is shown in Figure 3.

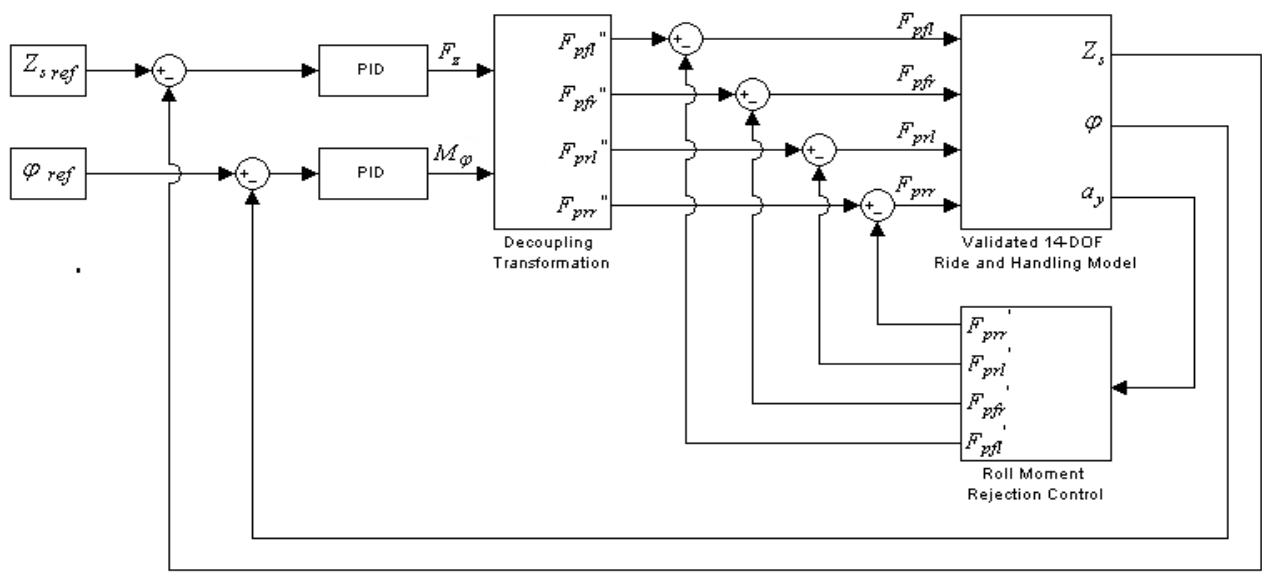

Fig. 3. The proposed control structure for arc system

The outputs of the outer loop controller are vertical forces to stabilize body bounce $\left(M_{z}\right)$ and moment to stabilize $\operatorname{roll}\left(M_{\theta}\right)$. These forces and moments are then distributed into target forces of the four pneumatic actuators produced by the outer loop controller. Distribution of the forces and moments into target forces of the four pneumatic actuators is performed using decoupling transformation subsystem. The outputs of the decoupling transformation subsystem namely the target forces of the four pneumatic actuators are then subtracted with the relevant outputs from the inner loop controller to produce the ideal 
target forces of the four pneumatic actuators. Decoupling transformation subsystem requires an understanding of the system dynamics in the previous section. The equivalent force and moment for heave, pitch and roll can be defined by

$$
\begin{gathered}
F_{z}=F_{p f l}^{\prime \prime}+F_{p f r}^{\prime \prime}+F_{p r l}^{\prime \prime}+F_{p r r}^{\prime \prime} \\
M_{\theta}=-F_{p f l}^{\prime \prime} l_{f}-F_{p f r}^{\prime \prime} l_{f}+F_{p r l}^{\prime \prime} l_{r}+F_{p r r}^{\prime \prime} l_{r} \\
M_{\varphi}=F_{p f l}^{\prime \prime}\left(\frac{w}{2}\right)-F_{p f r}^{\prime \prime}\left(\frac{w}{2}\right)+F_{p r l}^{\prime \prime}\left(\frac{w}{2}\right)-F_{p r r}^{\prime \prime}\left(\frac{w}{2}\right)
\end{gathered}
$$

where $F_{p f l}^{\prime \prime}, F_{p f r}^{\prime \prime}, F_{p r l}^{\prime \prime} F_{p r r}^{\prime \prime}$ are the pneumatic forces produced by outer loop controller in front left, front right, rear left and rear right corners, respectively. In the case of the vehicle input comes from steering wheel, the pitch moment can be neglected. Equations (37), (38) and (39) can be rearranged in matrix format as the following

$$
\left[\begin{array}{l}
F_{z}(t) \\
M_{\theta}(t) \\
M_{\varphi}(t)
\end{array}\right]=\left[\begin{array}{cccc}
1 & 1 & 1 & 1 \\
-l_{f} & -l_{f} & l_{r} & l_{r} \\
\frac{w}{2} & -\frac{w}{2} & \frac{w}{2} & -\frac{w}{2}
\end{array}\right]\left[\begin{array}{c}
F_{p f l}^{\prime \prime} \\
F_{p f r}^{\prime \prime} \\
F_{p r l}^{\prime \prime} \\
F_{p r r}^{\prime \prime}
\end{array}\right]
$$

For a linear system of equations $\mathbf{y}=\mathbf{C} \mathbf{x}$, if $\mathbf{C} \in \mathfrak{R}^{m x n}$ has full row rank, then there exists a right inverse $\mathbf{C}^{-1}$ such that $\mathbf{C}-1 \quad C=\mathbf{1}^{\mathbf{m x m}}$. The right inverse can be computed using $\mathbf{C}^{-}$ ${ }_{1}^{1}=\mathbf{C}^{\mathrm{T}}\left(\mathbf{C C}^{\mathrm{T}}\right)^{-1}$. Thus, the inverse relationship of equation (40) can be expressed as:

$$
\left[\begin{array}{c}
F_{p f l}^{\prime \prime} \\
F_{p f r}^{\prime \prime} \\
F_{p r l}^{\prime \prime} \\
F_{p r r}^{\prime \prime}
\end{array}\right]=\left[\begin{array}{ccc}
\frac{l_{r}}{2\left(l_{f}+l_{r}\right)} & -\frac{1}{2\left(l_{f}+l_{r}\right)} & \frac{1}{2 w} \\
\frac{l_{r}}{2\left(l_{f}+l_{r}\right)} & -\frac{1}{2\left(l_{f}+l_{r}\right)} & -\frac{1}{2 w} \\
\frac{l_{f}}{2\left(l_{f}+l_{r}\right)} & \frac{1}{2\left(l_{f}+l_{r}\right)} & \frac{1}{2 w} \\
\frac{l_{f}}{2\left(l_{f}+l_{r}\right)} & \frac{1}{2\left(l_{f}+l_{r}\right)} & -\frac{1}{2 w}
\end{array}\right]\left[\begin{array}{c}
F_{z} \\
M_{\theta} \\
M_{\varphi}
\end{array}\right]
$$

In the outer loop controller, PID control is applied for suppressing both body vertical displacement and body roll angle. The inner loop controller of roll moment rejection control is described as follows: during cornering, a vehicle will produce a sideway force namely cornering force at the body center of gravity. The cornering force generates roll moment to 
the roll center causing the body center of gravity to shift outward as shown in Figure 4 . Shifting the body center of gravity causes a weight transfer from the inside toward the outside wheels. By defining $b$ as the distance between body center of gravity and the roll center, roll moment is defined by

$$
M_{r}=M_{s} a_{y} b
$$

The two pneumatic actuators installed in outside wheels have to produce the necessary forces to cancel out the unwanted roll moments, whereas the forces of the two pneumatic actuators in inside wheels are set to zero. Pneumatic force to cancel out roll moment in each corner for counter clockwise steering wheel input is defined as:

$$
F_{p f r}^{\prime}=F_{p r r}^{\prime} \frac{M_{s} a_{y} b}{w / 2} \text { and } F_{p f l}^{\prime}=F_{p r l}^{\prime}=0
$$

Whereas, pneumatic force to cancel out roll moment in each corner for clockwise steering wheel input can be defined as:

$$
F_{p r l}^{\prime}=F_{p f l}^{\prime}=\frac{M_{s} a_{y} b}{w / 2} \text { and } F_{p f r}^{\prime}=F_{p r r}^{\prime}=0
$$

where,

$F_{p f l}^{\prime}=$ target force of pneumatic system at front left corner produced by inner loop controller $F_{p f r}^{\prime}=$ target force of pneumatic system at front right corner produced by inner loop controller

$F_{p r l}^{\prime}=$ target force of pneumatic system at rear left corner produced by inner loop controller

$F_{p r r}^{\prime}=$ target force of pneumatic system at rear right corner produced by inner loop controller

The ideal target forces for each pneumatic actuator are defined as the target forces produced by outer loop controller subtracted with the respective target forces produced by inner loop controller as the following:

$$
\begin{aligned}
& F_{p f l}=F_{p f l}^{\prime \prime}-F_{p f l}^{\prime} \\
& F_{p f r}=F_{p f r}^{\prime \prime}-F_{p f r}^{\prime} \\
& F_{p r l}=F_{p r l}^{\prime \prime}-F_{p r l}^{\prime} \\
& F_{p r r}=F_{p r r}^{\prime \prime}-F_{p r r}^{\prime}
\end{aligned}
$$




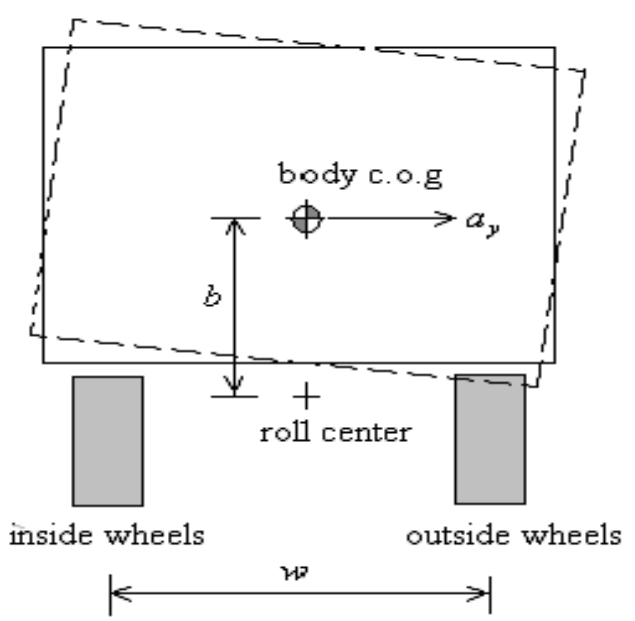

Fig. 4. Roll Moment Generated by Lateral Force

\section{Validation of 14-DOF Ride and Handling Model}

To verify the full vehicle ride and handling model, experimental works were performed using an instrumented experimental vehicle. This section provides the verification of ride and handling model using visual technique by simply comparing the trend of simulation results with experimental data using the same input conditions. Validation or verification is defined as the comparison of model's performance with a real system. Therefore, the validation is not meant as fitting the simulated data exactly to the measured data, but as gaining confidence that the vehicle handling simulation is giving insight into the behavior of the simulated vehicle. The test data are also used to check whether the input parameters for the vehicle model are reasonable. In general, model validation can be defined as determining the acceptability of a model using some statistical tests for deviance measures or subjectively using visual techniques.

\subsection{Instrumented Experimental Vehicle}

The data acquisition system (DAS) is installed into the experimental vehicle to obtain the experimental data from the real vehicle reaction to evaluate the vehicle performance in terms of lateral acceleration, body vertical acceleration, yaw rate and roll rate. The DAS uses several types of transducers such as single axis accelerometer to measure the sprung mass and unsprung mass accelerations for each corner, tri-axial accelerometer to measure lateral, vertical and longitudinal accelerations at the body center of gravity, steering wheel sensor and tri-axial gyroscopes for the yaw rate, pitch rate and roll rate. The multi-channel $\mu$ MUSYCS system Integrated Measurement and Control (IMC) is used as the DAS system. Online FAMOS software as the real time data processing and display function is used to ease the data collection. The installation of the DAS and sensors to the experimental vehicle can be seen in Figure 5. 


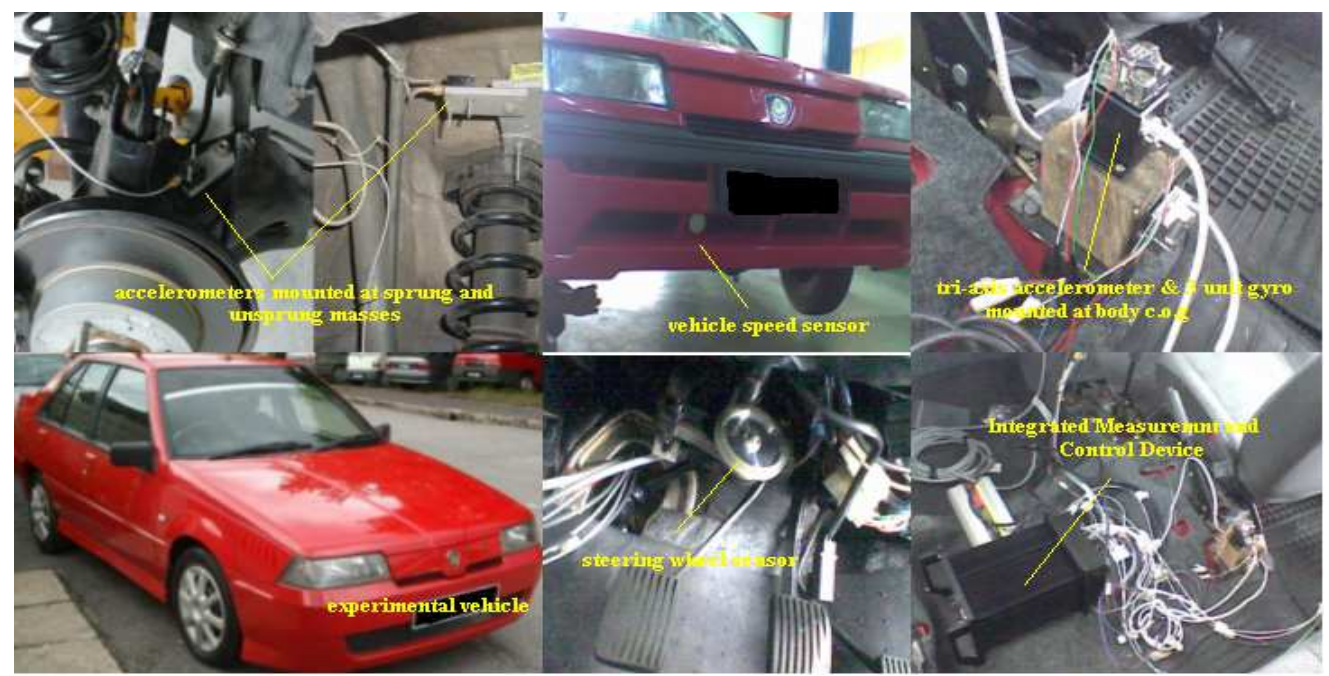

Fig. 5. Instrumented experimental vehicle

\subsection{Validation Procedures}

The dynamic response characteristics of a vehicle model that include yaw response, lateral acceleration, slip angle in each tire and roll rate can be validated using experimental test through several handling test procedures namely step steer test and double lane change (DLC) test. Step steer test is intended to study transient response of the vehicle under steering wheel input. In this study, step steer tests were performedwith 180 degrees clock wise at $50 \mathrm{~km} / \mathrm{h}$. On the other hand, double-lane change test is used to evaluate road holding of the vehicle during crash avoidance. In this study, the speed of $80 \mathrm{~km} / \mathrm{h}$ was set for the double-lane change test.

\subsection{Model Validation Results}

In experimental works, all the experimental data were filtered using $5^{\text {th }}$ order Butterworth low pass filter with the cut-off frequency of $5 \mathrm{~Hz}$. It is necessary to note that the measured steering angle from the steering wheel sensorwas used as the input of simulation model. For the simulation model, tire parameters are obtained from Szostak et al. (1988) and Singh et al. (2000). The results of model verification for 180 degrees step steer test at $50 \mathrm{~km} / \mathrm{h}$ is shown in Figure 6 to 13.

Figure 6 shows the steering wheel input applied for the step steer test. It can be seen that the trends between simulation results and experimental data are almost similar with acceptable error. The small difference in magnitude between simulation and experimental results is due to the simplification in vehicle dynamics modeling where the effects of anti roll bar were completely ignored. In fact, the anti roll bar plays an important role in reducing the vertical and roll responses of vehicle body. In simulation model, vehicle body is assumed to be rigid. It can be another source of deviation since the body flexibility can influence the roll effects of the vehicle body. 
In terms of yaw rate, lateral acceleration and body roll angle, it can be seen that there are quite good comparisons during the initial transient phase as well as during the subsequent steady state phase as shown in Figures 7 to 9. Slip angle responses of the front tires also show satisfying comparison with only small deviation in the transition area between transient and steady state phases as shown in Figures 10 and 11.

It can also be noted that the slip angle responses of all tires in the experimental data are slightly higher than the slip angle data obtained from the simulation particularly for the rear tires as can be seen in Figures 12 and 13. This is due to the fact that it is difficult for the driver to maintain a constant speed during maneuvering. In simulation, it is also assumed that the vehicle is moving on a flat road during step steer maneuver. In fact, it is observed that the road profiles of test field consist of irregular surface. This can be another source of deviation on slip angle response of the tires.

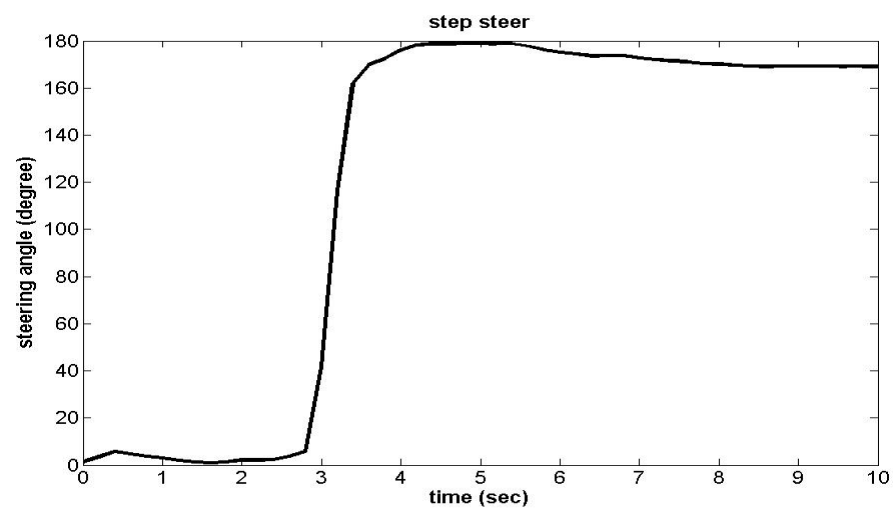

Fig. 6. Steer angle input for 180 deg step steer at $50 \mathrm{~km} / \mathrm{h}$

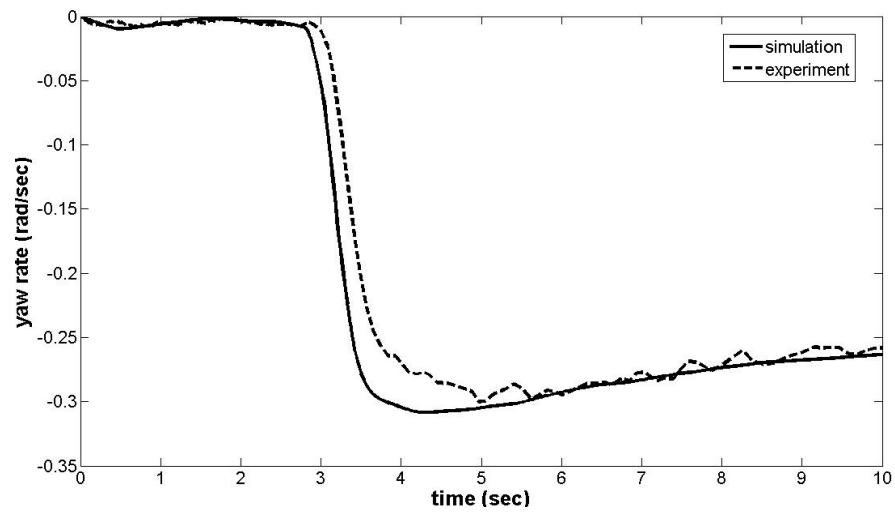

Fig. 7. Yaw rate response for 180 deg step steer at $50 \mathrm{~km} / \mathrm{h}$ 


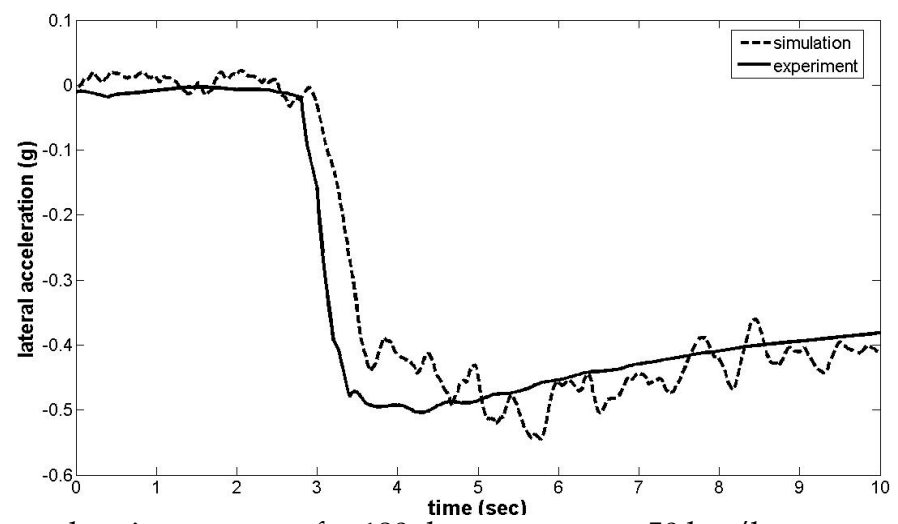

Fig. 8. Lateral acceleration response for $180 \mathrm{deg}$ step steer at $50 \mathrm{~km} / \mathrm{h}$

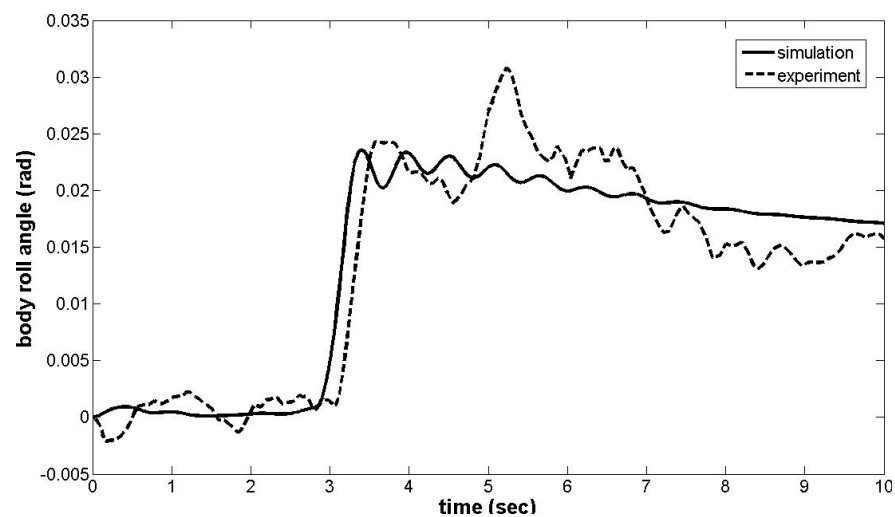

Fig. 9. Roll angle response for $180 \mathrm{deg}$ step steer at $50 \mathrm{~km} / \mathrm{h}$

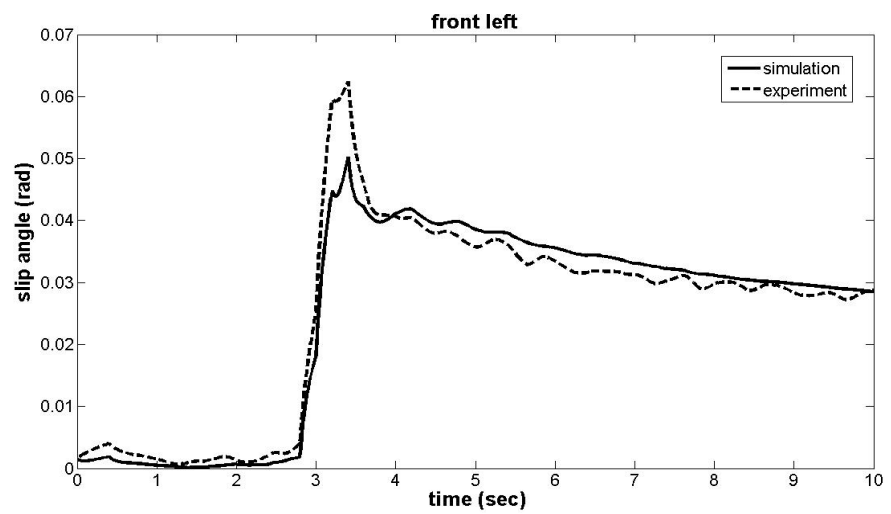

Fig. 10. Slip angle at the front left tire for $180 \mathrm{deg}$ step steer at $50 \mathrm{~km} / \mathrm{h}$ 


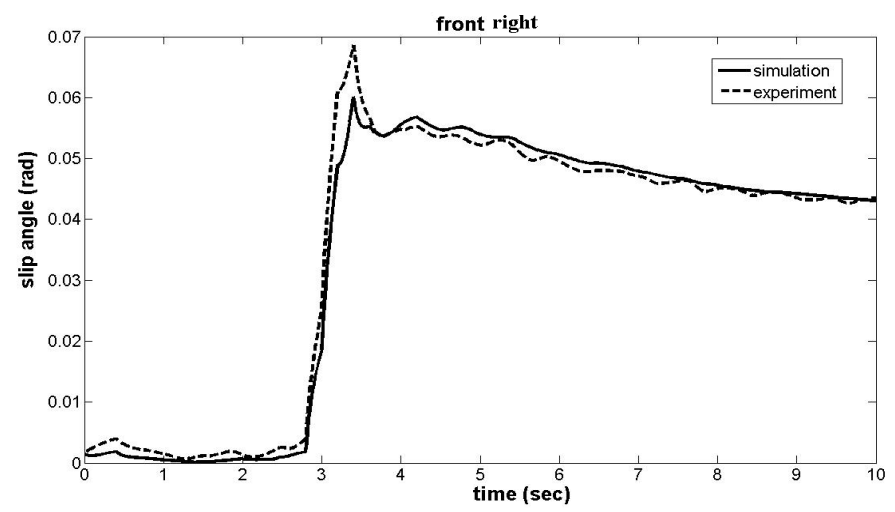

Fig. 11. Slip angle response at front right tire for $180 \mathrm{deg}$ step steer at $50 \mathrm{~km} / \mathrm{h}$

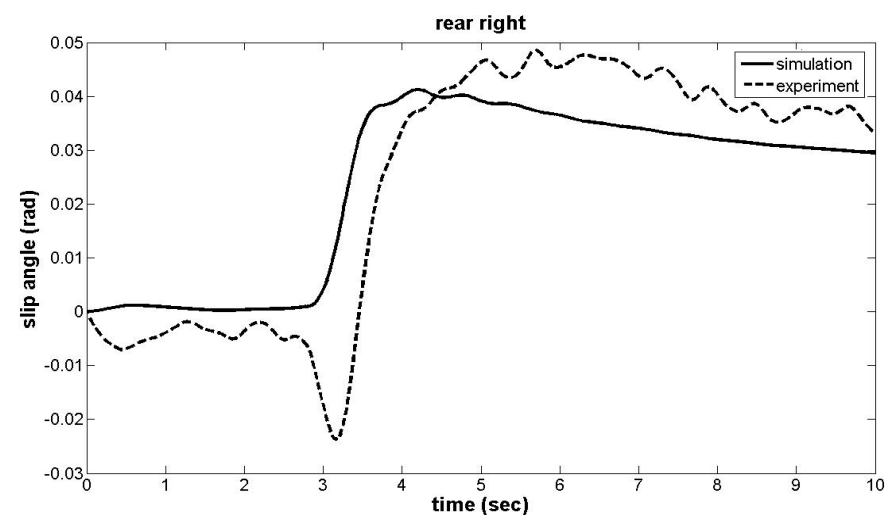

Fig. 12. Slip angle at the rear right tire for $180 \mathrm{deg}$ step steer at $50 \mathrm{~km} / \mathrm{h}$

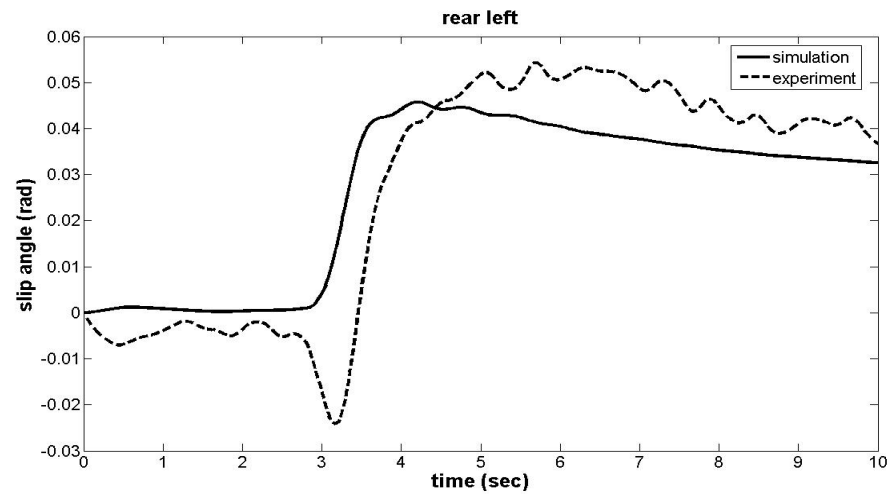

Fig. 13. Slip angle at the rear left tire for $180 \mathrm{deg}$ step steer at $50 \mathrm{~km} / \mathrm{h}$

The results of double lane change test indicate that measurement data and the simulation results agree with a relatively good accuracy as shown in Figures 14 to 21. Figure 14 shows 
the measured steering wheel input from double lane change test maneuver which is also used as the input for the simulation model. In terms of yaw rate, lateral acceleration and body roll angle, it is clear that the simulation results closely follow the measured data with minor difference in magnitude as shown in Figures 15 to 17. The minor difference in magnitude and small fluctuation occurred on the measured data is due to the body flexibility which was ignored in the simulation model. The minor difference in magnitude between measured and simulated data can also be caused by one of the modeling assumptions namely the effects of anti roll bar which is completely ignored in simulation model.

In terms of tire side slip angles, the trends of simulation results have a good correlation with experimental data as can be seen in Figures 18 to 21. Almost similar to the validation results obtained from step steer test, the slip angle responses of all tires in experimental data are higher than the slip angle data obtained from the simulation particularly for the rear tires. Again, this is due to the difficulty of the driver to maintain a constant speed during double lane change maneuver. Assumption in simulation model that the vehicle is moving on a flat road during double lane change maneuver is also very difficult to realize in practice. In fact, road irregularities of the test field may cause the change in tire properties during vehicle handling test. Assumption of neglecting the steering inertia have the possibility in lowering down the magnitude of tire side slip angle in simulation results compared to the measured data.

Overall, it can be concluded that the trends between simulation results and experimental data are having good agreement with acceptable error. The error could be significantly reduced by fine tuning of both vehicle and tire parameters. However, excessive fine tuning works can be avoided since in control oriented model, the most important characteristic is the trend of the model response. As long as the trend of the model response is closely similar with the measured response with acceptable deviation in magnitude, it can be said that the model is valid. The validated model will be used in conjunction with the proposed controller structure of the ARC system in the next section.

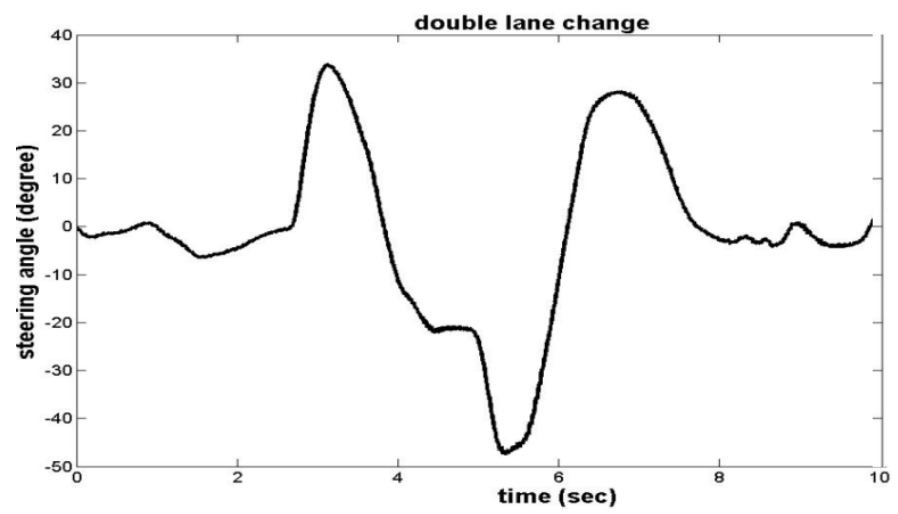

Fig. 14. Steer angle input for $80 \mathrm{~km} / \mathrm{h}$ double lane change maneuver 


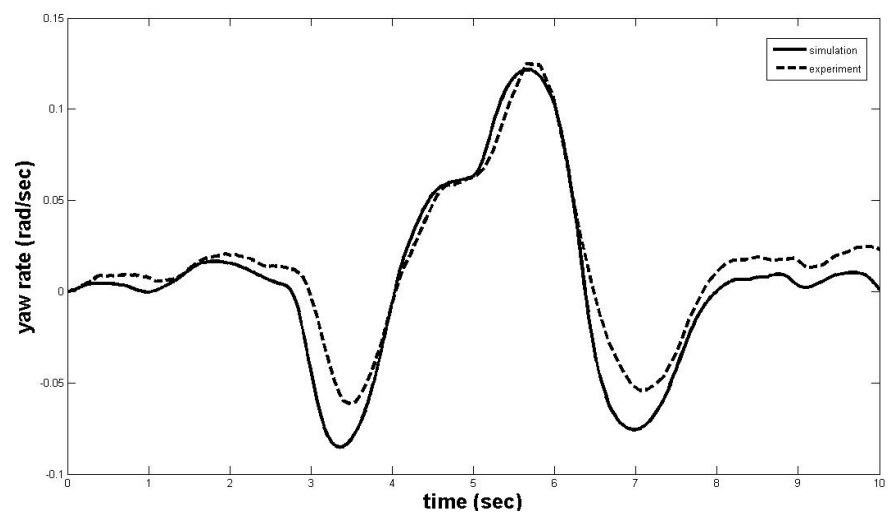

Fig. 15. Yaw rate response for $80 \mathrm{~km} / \mathrm{h}$ double lane change maneuver

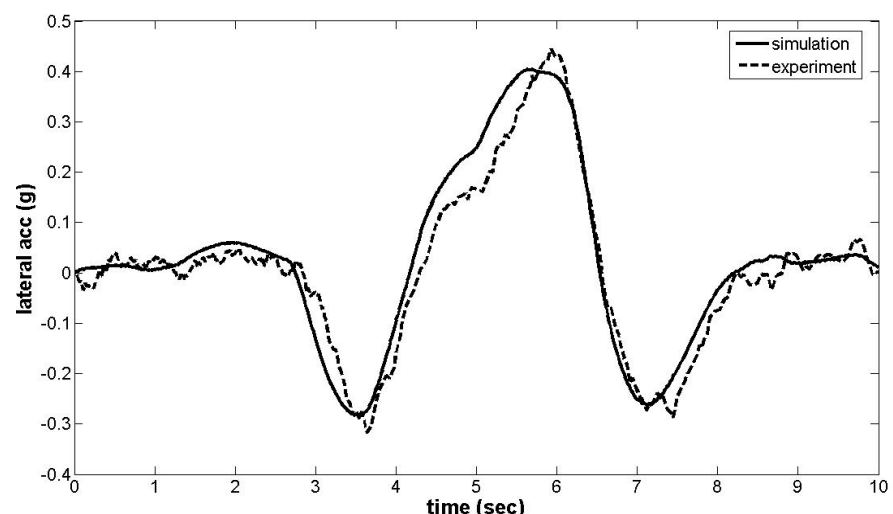

Fig. 16. Lateral acceleration response for $80 \mathrm{~km} / \mathrm{h}$ double lane change maneuver

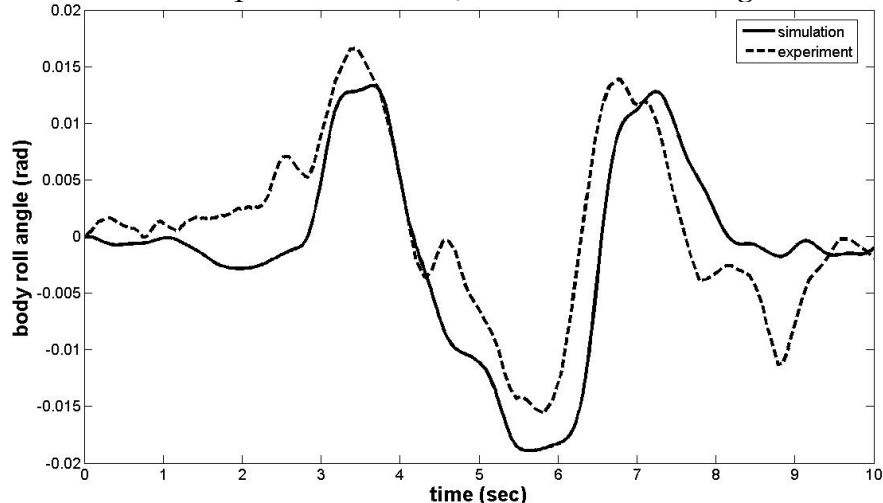

Fig. 17. Roll angle response for $80 \mathrm{~km} / \mathrm{h}$ double lane change maneuver 


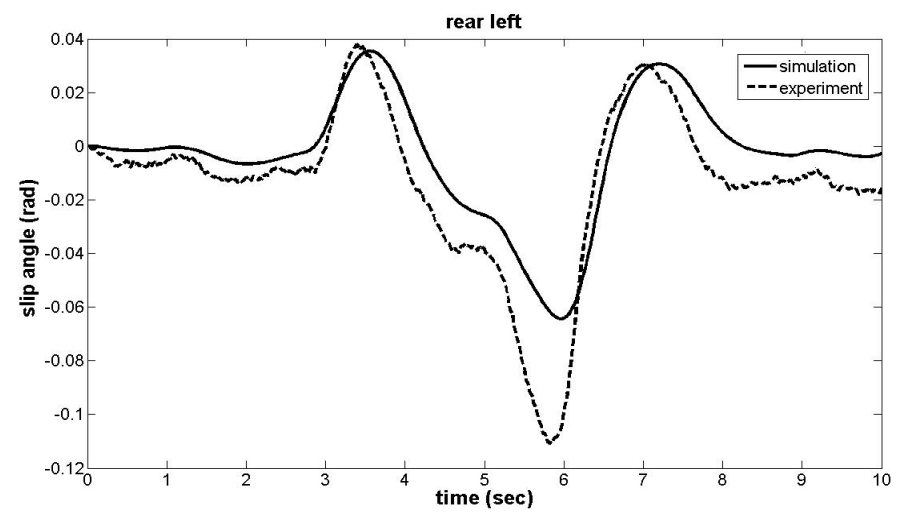

Fig. 18. Slip angle at the front left tire for $80 \mathrm{~km} / \mathrm{h}$ double lane change maneuver

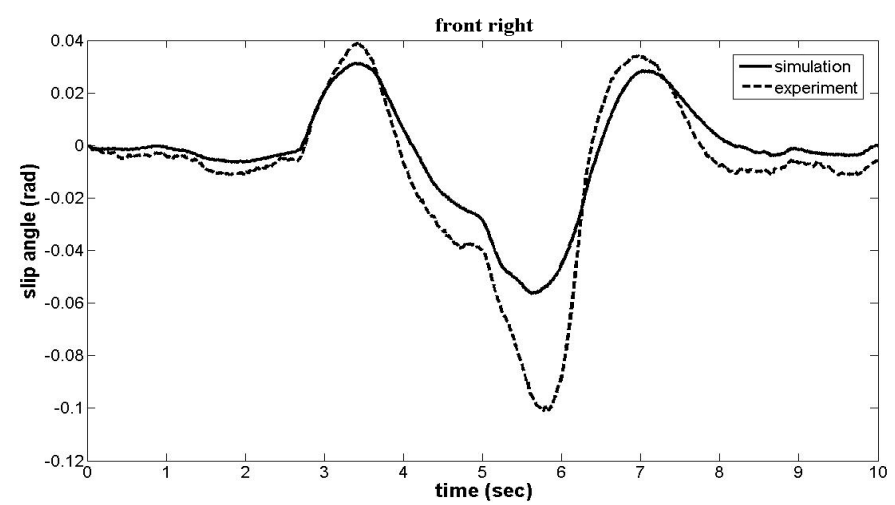

Fig. 19. Slip angle at the front right tire for $80 \mathrm{~km} / \mathrm{h}$ double lane change maneuver

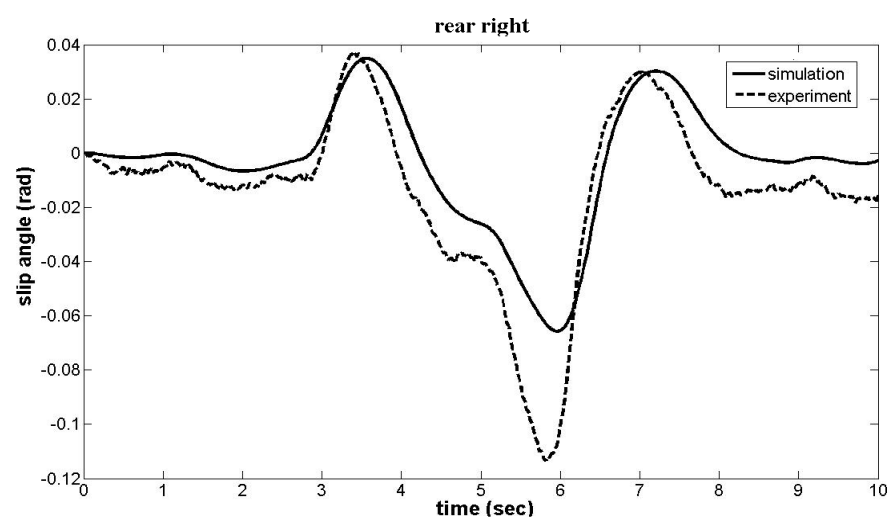

Fig. 20. Slip angle at the rear right tire for $80 \mathrm{~km} / \mathrm{h}$ double lane change maneuver 


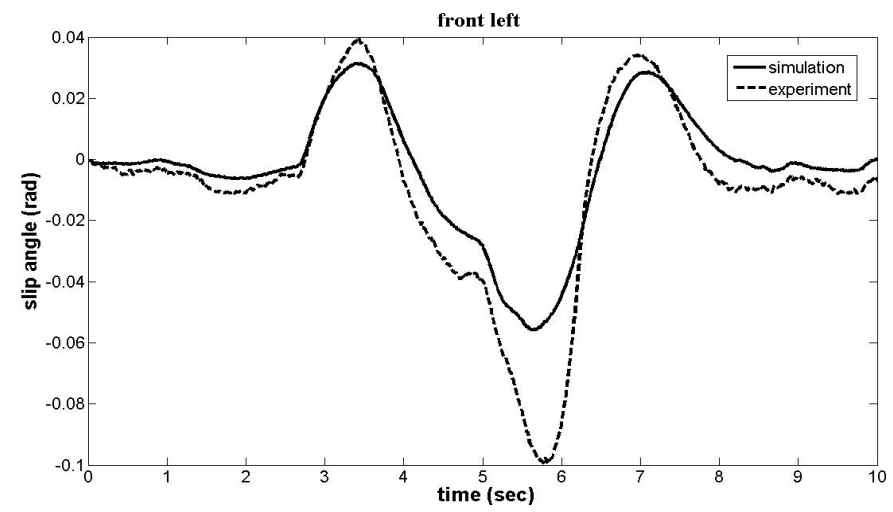

Fig. 21. Slip angle at the rear left tire for $80 \mathrm{~km} / \mathrm{h}$ double lane change maneuver

\section{Performance Assessment of the Proposed Control Structure for ARC System}

This section describes the results of performance study of the proposed control structure for the pneumatically actuated ARC system namely PID with roll moment rejection control. Performance of the vehicle with passive system is used as a basic benchmark. To investigate the advantage of additional roll moment rejection loop, the performance of the proposed controller is also compared with PID without roll moment rejection loop. This section begins with introducing all the parameters used in this simulation study, followed by the presentation of the controller performance in step steer and double lane change tests. The PID with roll moment rejection control for ARC system is evaluated for its performance at controlling the lateral dynamics of the vehicle according to the following performance criteria namely body vertical acceleration, body heave, body roll rate and body roll angle.

\subsection{Simulation Parameters}

The simulation study was performed for a period of 10 seconds using Heun solver with a fixed step size of 0.01 second. The controller parameters are obtained using trial and error technique with some sensitivity studies. The numerical values of the 14-DOF full vehicle model parameters and Calspan tire model parameters as well as the controller parameters are given in the Appendix.

\subsection{Performance of ARC System During Step Steer Test}

The simulation results of body roll angle and body roll rate at the body centre of gravity on 180 degrees step steer test at $50 \mathrm{~km} / \mathrm{h}$ are shown in Figures 22 and 23 respectively. It can be seen that the performance of PID control with roll moment rejection loop can outperform its counterpart namely passive system and PID control without roll moment rejection loop. In terms of the roll angle response, it is clear that the additional roll moment rejection loop can effectively reduce the magnitude of the roll angle response. Improvement in roll motion during maneuvering can enhance the stability of the vehicle in lateral direction.

In terms of the roll rate response, PID control with roll moment rejection loop shows significant improvement over passive and PID control without roll moment rejection loop 
particularly in the transient response phase area. At steady state response, PID control with roll moment rejection loop shows slight improvement in terms of settling time over PID control without roll moment rejection loop and significant improvement over passive system. Again, the advantage of the additional roll moment rejection loop is shown by reducing the magnitude of the roll rate response. Improvement in both roll rate response and the settling time during maneuvering can increase the stability level of the vehicle in the presence of steering wheel input from the driver.

Body vertical acceleration and body heave responses of the vehicle at the body center of gravity are presented in Figures 24 and 25 respectively. From the body vertical acceleration response, both PID control with and without roll moment rejection loops are able to drastically reduce unwanted vertical acceleration compared to the passive system. It can be seen, the capability of the controller in lowering down the magnitude of body acceleration and in speeding up the settling time. Improvement in vertical acceleration at the body center of gravity will enhance the comfort level of the vehicle as well as avoiding the driver from losing control of the vehicle during maneuvering.

The main goal of ARC system is to keep the vehicle body remain flat in any driving maneuvers. From the body heave response, it is clear that the performance of PID control with roll moment rejection loop is significantly better than that of passive system and PID control without roll moment rejection loop. It means that PID control with roll moment rejection loop shows less vertical displacement during step steer maneuver. This will also enhance the comfort level of the vehicle as well as avoiding the driver from losing control of the vehicle.

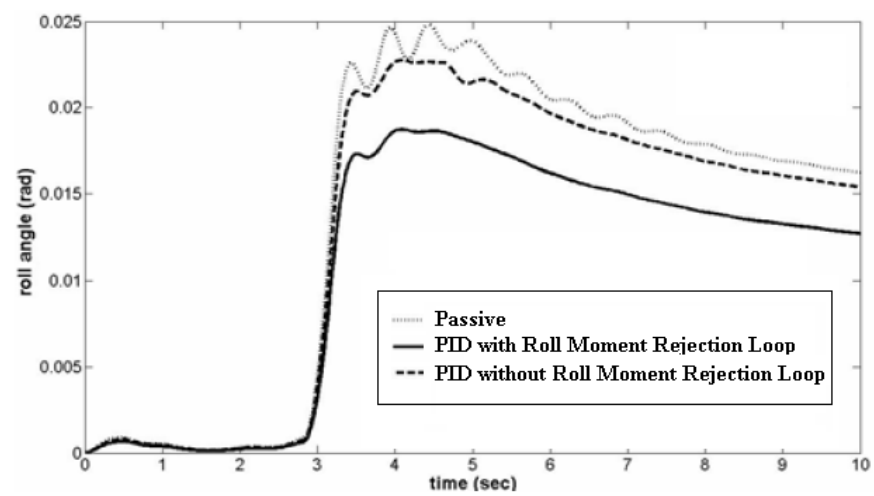

Fig. 22. Roll angle response of ARC System for 180 degrees Step Steer Test at $50 \mathrm{~km} / \mathrm{h}$ 


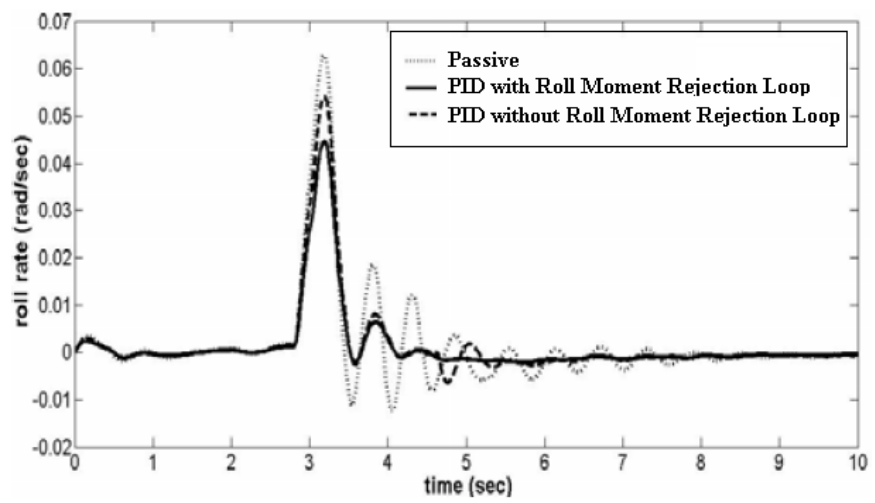

Fig. 23. Roll rate response of ARC System for 180 degrees Step Steer Test at $50 \mathrm{~km} / \mathrm{h}$

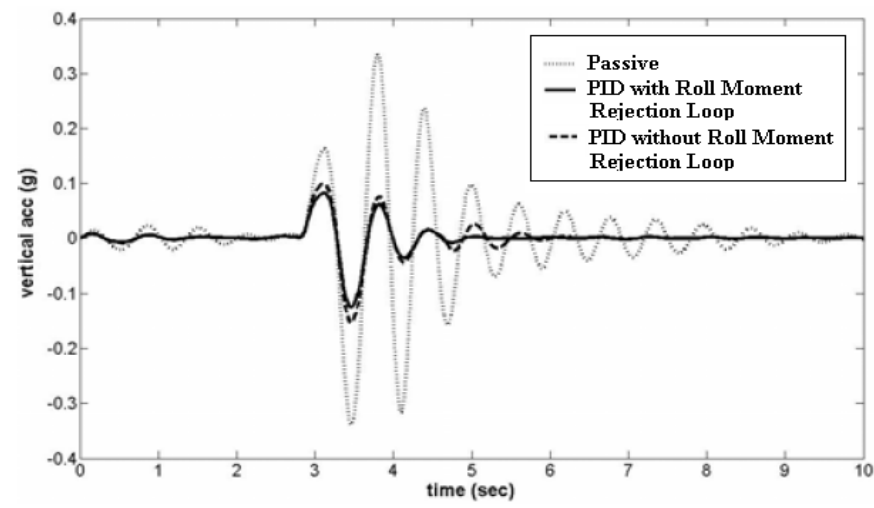

Fig. 24. Vertical acceleration response of ARC System for 180 degrees Step Steer Test at 50 $\mathrm{km} / \mathrm{h}$

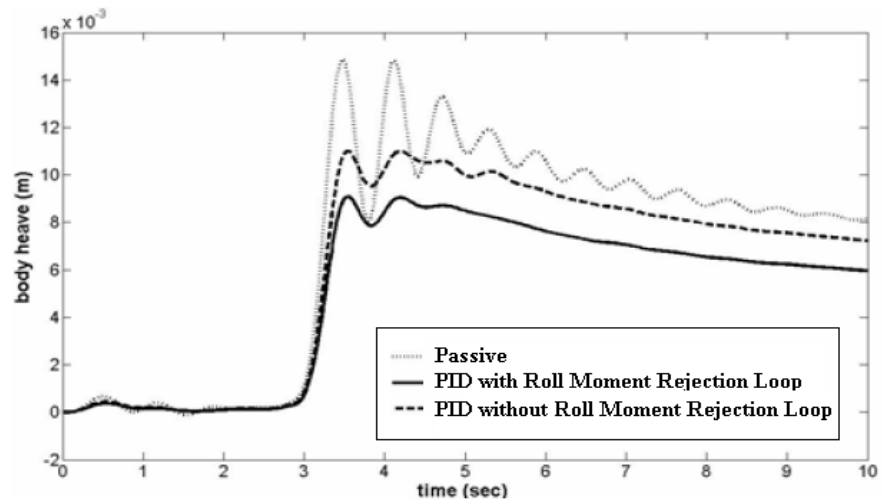

Fig. 25. Vertical displacement response at the body cog of ARC System for 180 degrees Step Steer Test at $50 \mathrm{~km} / \mathrm{h}$ 


\subsection{Performance of ARC System During Double Lane Change Test}

The simulation results of body roll angle and body roll rate at the body centre of gravity during double lane change test at $80 \mathrm{~km} / \mathrm{h}$ are shown in Figures 26 and 27 respectively. Double lane-change is know as a test that measures the maneuverability of the vehicle. In real life, a double lane change often occurs when the driver is trying to avoid an accident. This sudden maneuver can easily cause the vehicle to tip on two wheels, resulting in a rollover. From Figures 26 and 27, it can be observed that the maneuverability of the vehicle increases by implementing ARC system. In the case of the driver makes an abrupt swerve like double lane change maneuver, improvement in both roll rate and roll angle responses indicate that the possibility of roll over can be significantly reduced using ARC system. From the figures, the performance benefit of additional roll moment rejection loop is also observed.

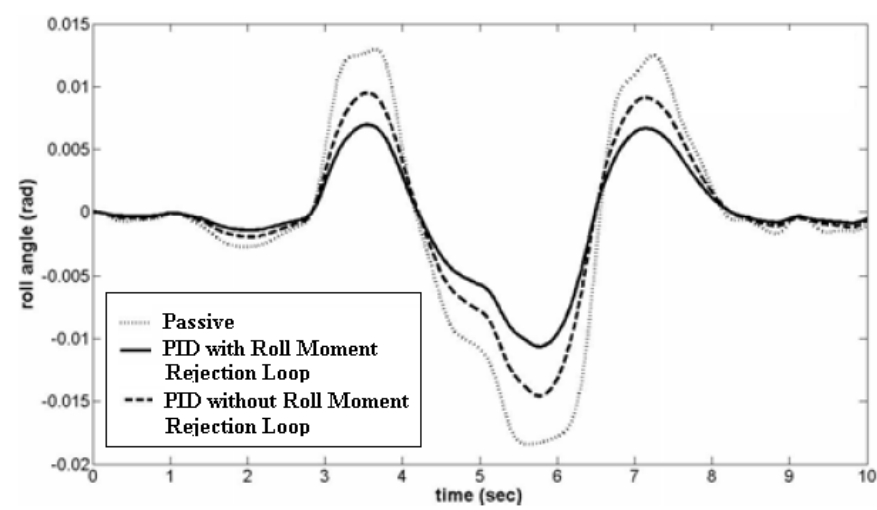

Fig. 26. Roll angle response of ARC System for $80 \mathrm{~km} / \mathrm{h}$ double lane change

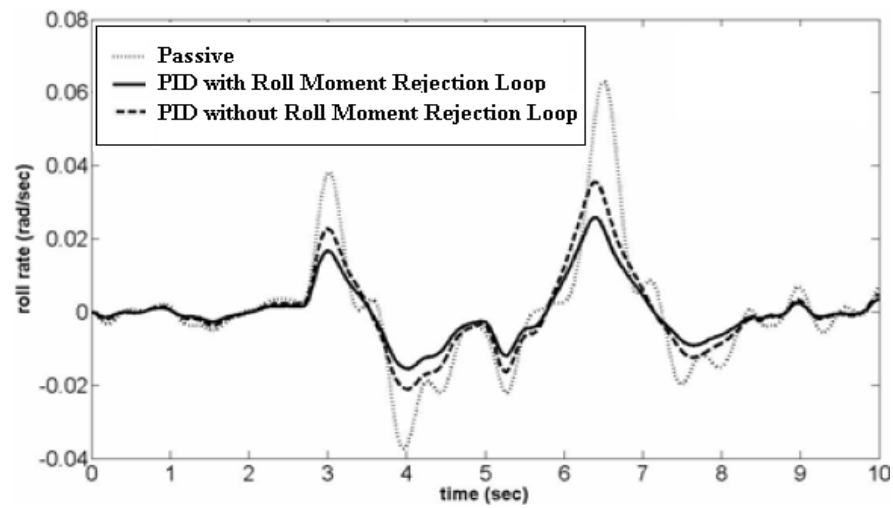

Fig. 27. Roll rate response of ARC System for $80 \mathrm{~km} / \mathrm{h}$ double lane change 


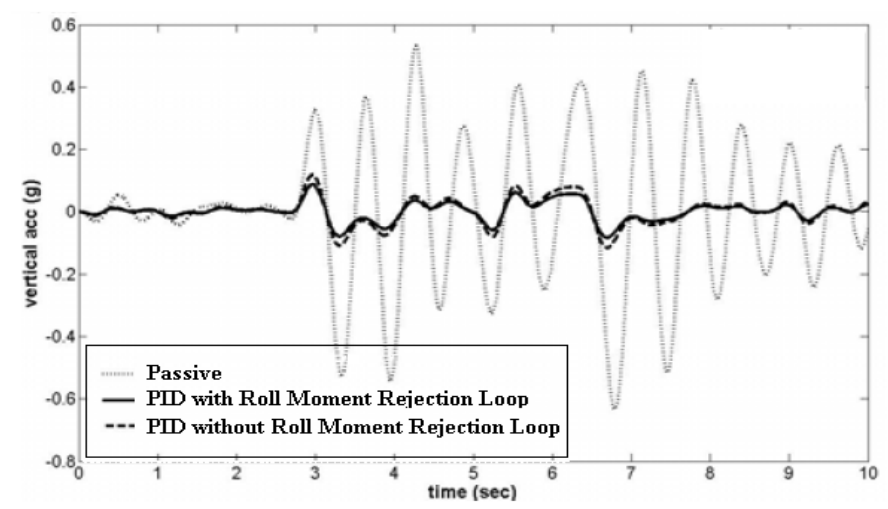

Fig. 28. Vertical acceleration of ARC System for $80 \mathrm{~km} / \mathrm{h}$ double lane change

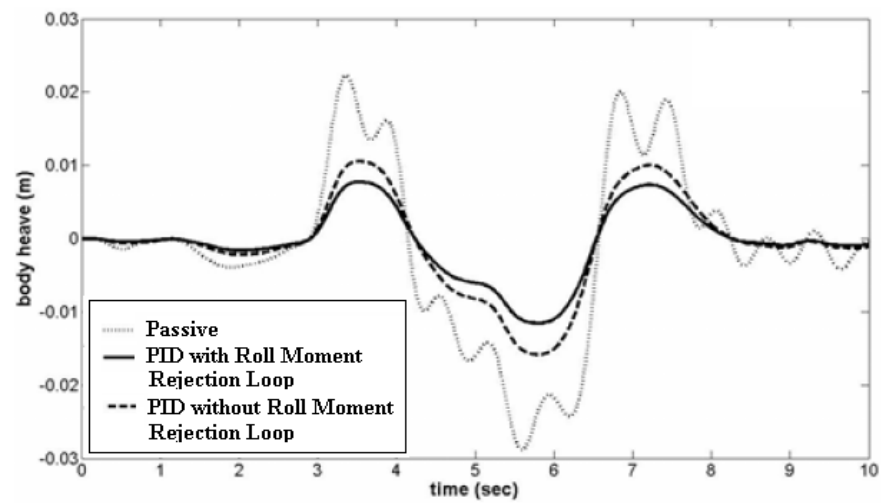

Fig. 29. Vertical displacement response of ARC System for $80 \mathrm{~km} / \mathrm{h}$ double lane change

Body vertical acceleration and body heave response are presented in Figures 28 and 29. It can be concluded that PID controller with and without roll moment rejection loop for ARC system are able to improvement significantly the ride performance compared to the passive system. Again, the performance benefit of additional roll moment rejection loop is also observed from the figures. Enhancement in ride performance may trim down the rate of driver fatigue and reduce the risk of the driver losing control of the vehicle. It can also be observed from the figures that the performance benefit of additional roll moment rejection loop is minor.

\section{Experimental Evaluation of the Proposed Control Structure for ARC System}

This section describes the experimental results of ARC system implemented on the instrumented experimental vehicle. Performance of the vehicle equipped with ARC system is compared with passive system in several maneuvers namely step steer and double lane change tests. The response of the passive vehicle is used as a basic benchmark for performance of ARC system. The ARC system is evaluated for its performance at controlling the lateral dynamics of the vehicle according to the following performance criteria namely body vertical acceleration, body vertical displacement, body roll rate and body roll angle. 


\subsection{Installation of ARC System into the Instrumented Experimental Vehicle}

The instrumented experimental vehicle consists of two groups of transducers namely vehicle states sensors and actuator sensors. The vehicle states sensors consist of one unit of K-Beam ${ }^{\circledR}$ Capacitive Triaxial Accelerometer 8393 B10 manufactured by Kistler and three units of CRS03 gyro by Silicon Sensing that are installed in the body centre of gravity of the experimental vehicle. The triaxial accelerometer is used to provide measurement data of body vertical, lateral, and longitudinal accelerations while the gyros is used to measure pitch, yaw and roll motions. The vehicle states sensors also consist of one unit of DRS1000 Doppler Radar Speed Sensor manufactured by GMH Engineering to record the real-time vehicle speed during experiment and one unit of Linear Encoder to record the real time steer angle. The actuator sensors consist of four units of LCF451 Load Cells manufactured by Futek to measure the actuator forces. The multi-channel $\mu$-MUSYCS system Integrated Measurement and Control (IMC) is used as the data acquisition system. It is installed into experimental vehicle to collect the experimental data from the transducers to control the vehicle performance in terms of body lateral acceleration, body vertical acceleration, and body roll rate. Online FAMOS software as the real time data processing and display function is used to ease the data collection. More detail specifications of the transducers and the data acquisition system are listed in the appendix.

The pneumatic actuator as the main component of the ARC system consists of 4 unit of pneumatic compact cylinders which are installed in parallel arrangement with passive suspension system. A double acting pneumatic compact cylinder of SDA80x75 is used in this experimental test which has bore size of $80 \mathrm{~mm}$ and $75 \mathrm{~mm}$ in stroke length. Another components are 5/3 way solenoid valve (center exhaust), $2.5 \mathrm{HP}$ air compressor and the current driver. The 5/3 way solenoid valves of SY7420-5LZD with double coil specification of $24 \mathrm{~V}$ and $300 \mathrm{~mA}$ are installed with the cylinders. The installation of the data acquisition system, sensors and pneumatic system to the experimental vehicle can be seen in Figure 30.

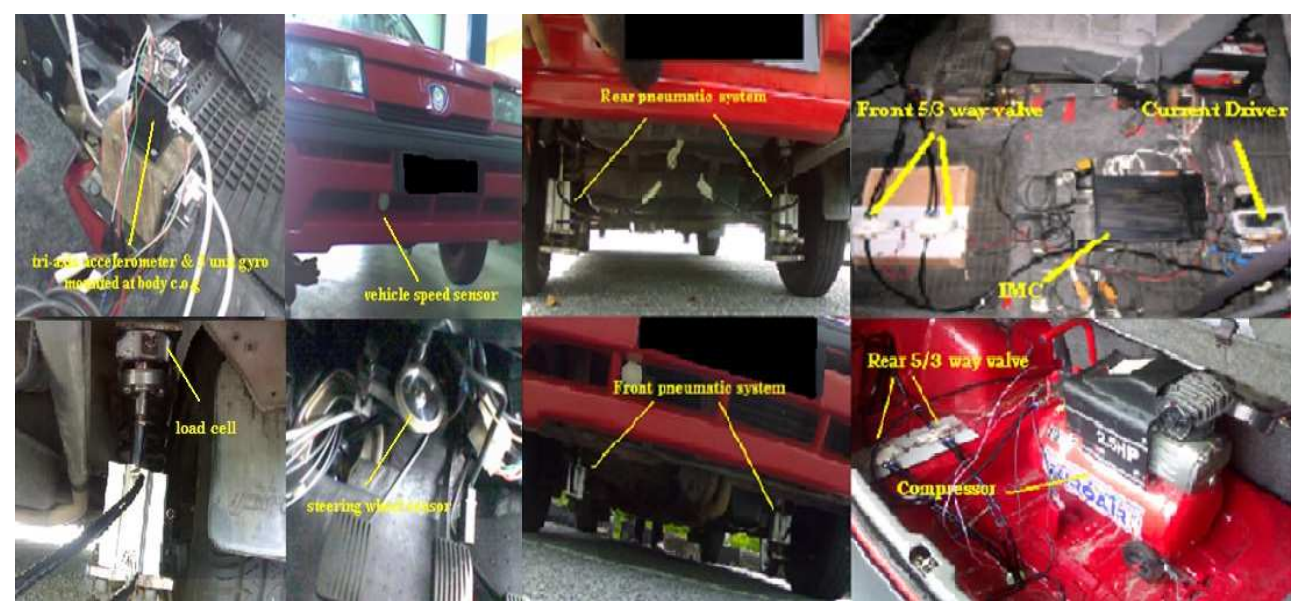

Fig. 30. Four units of pneumatic system installed in instrumented experimental vehicle 


\subsection{Experimental Parameters}

The ARC system is performed in experimental test with two types of maneuver tests namely step steer test and double lane change test. In step steer test, the vehicle begins moving in a straight line with the constant speed of $50 \mathrm{~km} / \mathrm{h}$ and then the steering suddenly turned 160 degrees clockwise. The double lane change and slalom tests were performed with the constant speed of $50 \mathrm{~km} / \mathrm{h}$ based on the test track as illustrated in Figure 31.

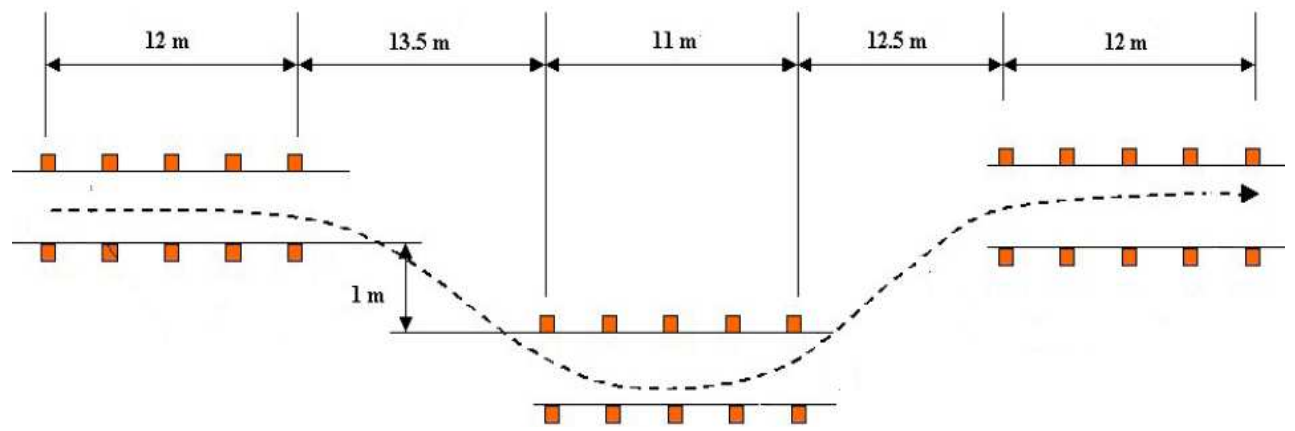

Fig. 31. The track for double lane change test

\subsection{Experimental Performance of ARC System during Step Steer Test}

Figure 32 shows the visual comparison of experimental results between passive system and vehicle equipped with ARC system during steep steer test. It can be seen that the roll angle of vehicle is reduced for vehicle equipped with ARC system compared to the passive system and able to reduce the possibility of vehicle rollover.

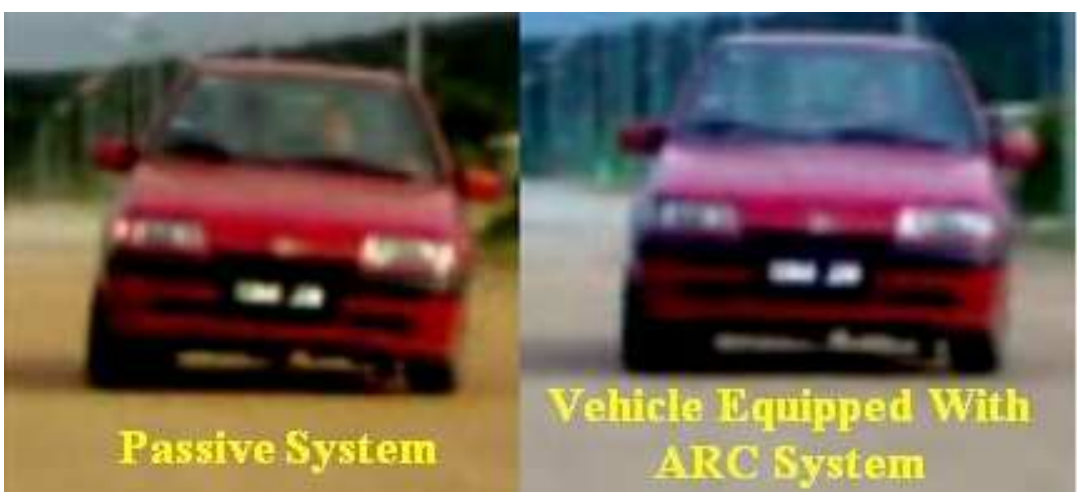

Fig. 32. Visual comparison of passive system and vehicle equipped with ARC system during step steer test

The experimental result of body roll angle at body centre of gravity during step steer test is shown in Figure 33(a). It can be seen that the performance of vehicle equipped with ARC system is better than passive system by reducing the magnitude of body roll angle. The vehicle equipped with ARC system also showing a significant reduction of roll rate at body centre of gravity as compared with passive system as shown in Figure 33(b). The vehicle 
equipped with ARC system shows an improvement response with respect to passive system by reducing the magnitude of body roll rate.

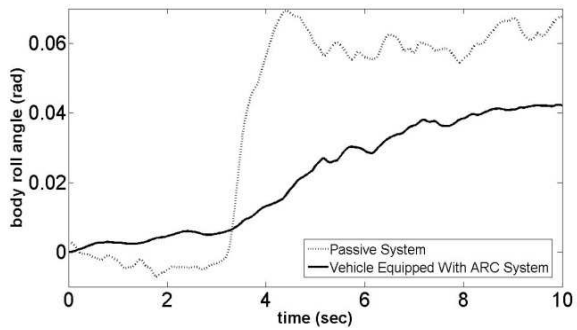

a) Roll angle response at the body center of gravity

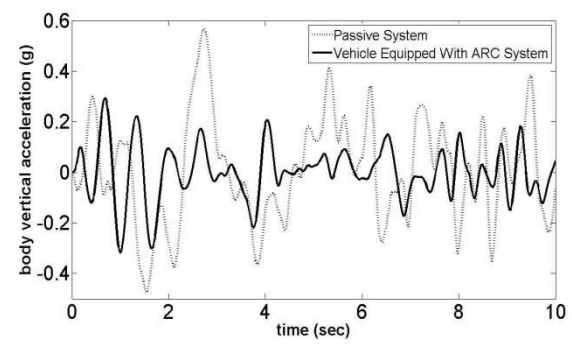

c) Vertical acceleration response at the body center of gravity

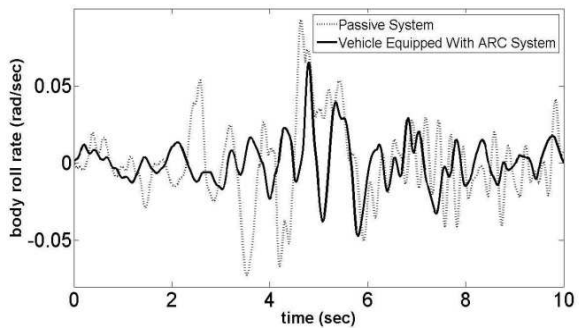

b) Roll rate response at the body center of gravity

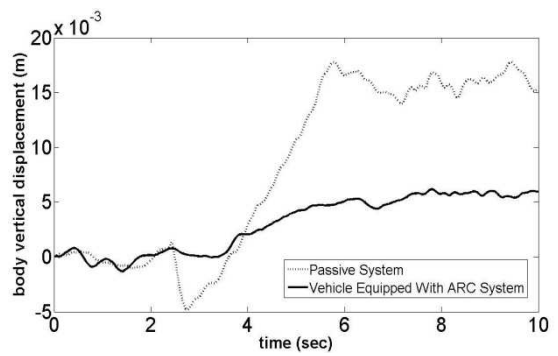

d) Vertical displacement response at the at the body center of gravity

Fig. 33. Experimental results of passive system and vehicle equipped with ARC system for 160 degrees step steer test at $50 \mathrm{~km} / \mathrm{h}$

The body vertical displacement performance at body centre of gravity obtained from the experimental result is shown in Figure 33(c). It can be seen that there is an improvement on vertical displacement of vehicle equipped with ARC system over passive system. The experimental result of vehicle equipped with ARC system is having smaller magnitude of vertical displacement than that of passive system. Vehicle equipped with ARC system also offer significant improvement on body vertical acceleration as shown in Figure 33(d). It can be seen that the ARC system is more capable in lowering down the magnitude of body vertical acceleration compared to passive system.

\subsection{Experimental Performance of ARC System during Double Lane Change Test}

Figure 34 shows the visual comparison of experimental results between passive system and vehicle equipped with ARC system during double lane change test. It can be seen that the stability of the vehicle equipped with ARC system is improved compare to passive system. 


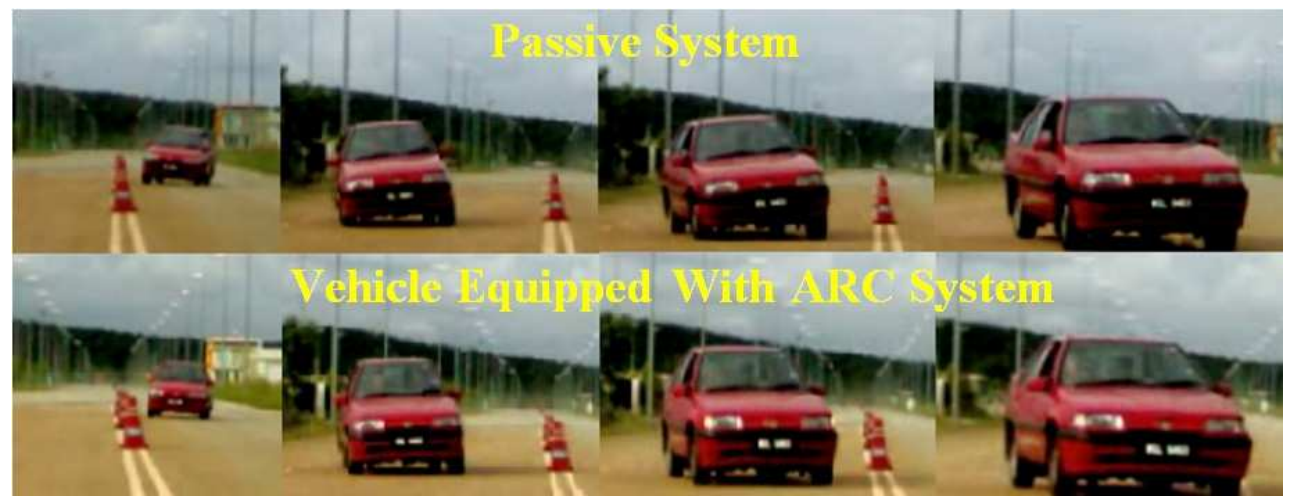

Fig. 34. Visual comparison of experimental results between passive system and vehicle equipped with ARC system during double lane change test

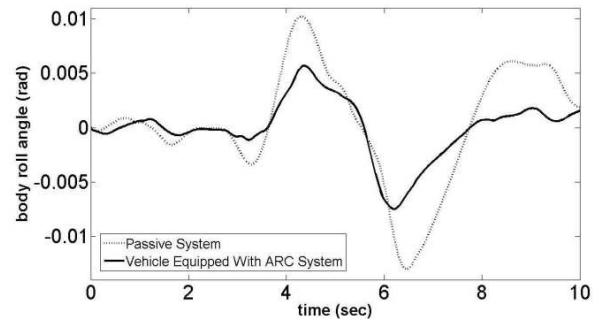

a) Roll angle response at the body center of gravity

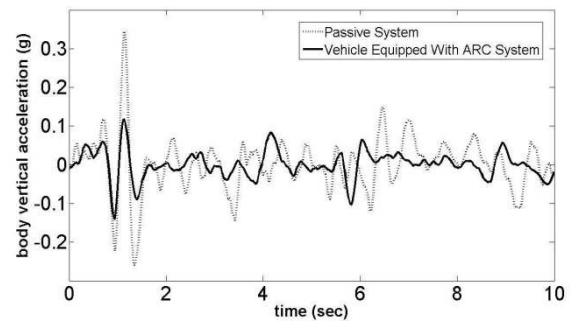

c) Vertical acceleration response at the body center of gravity

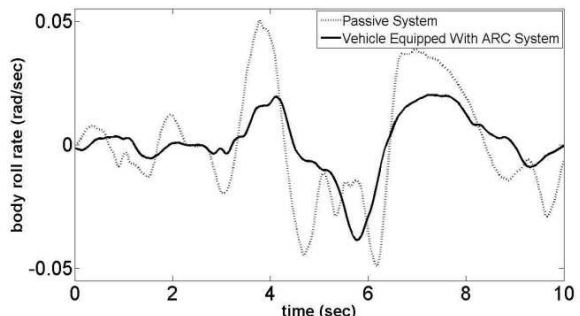

b) Roll rate response at the body center of gravity

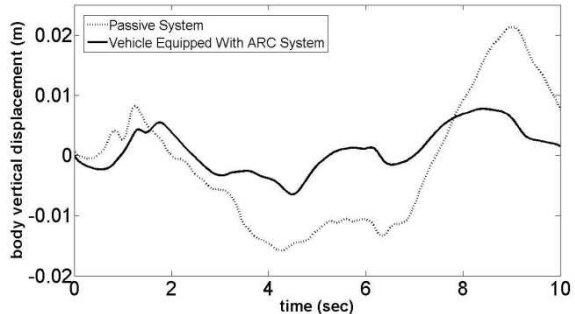

d) Vertical displacement response at the body center of gravity

Fig. 35. Experimental results of passive system and vehicle equipped with ARC system for DLC test at $50 \mathrm{~km} / \mathrm{h}$

From Figure 35(a) it can be seen that the body roll angle response of the passive system is higher than the body roll angle response of the vehicle equipped with ARC system. Therefore, it can be said that the vehicle equipped with ARC system is more stable and easier to avoid an obstacle during driving than passive system. The vehicle equipped with ARC system also show more reduction in magnitude in terms of roll rate response at body 
centre of gravity compared to passive system. The experimental result of roll rate is presented in Figure 35(b). It indicates that the overall vehicle roll rate behavior is improved with the vehicle equipped with ARC system to passive system

The experimental result of body vertical displacement at the body centre of gravity is shown in Figure 35(c). From the result it can be said that in terms of body vertical displacement at the body centre of gravity, the performance of the vehicle equipped with ARC system is better than the passive system. The vertical acceleration at body centre of gravity obtained from the experiment is shown in Figure 35(d). It can be seen that there is an improvement on vertical acceleration of vehicle equipped with ARC system compared to passive system. It can be seen clearly that the ARC system is effective in improving the performance of vehicle body from unwanted body motions namely vertical acceleration. Overall, It can be concluded that the ARC system is able to reduce the unwanted body motion in vertical direction.

\section{Conclusions}

A 14-DOF full vehicle model for passenger vehicle which consists of ride, handling and Calspan tire subsystems has been developed. An instrumented experimental vehicle has been developed to validate the 14-DOF model with the necessary sensors and data acquisition system installed inside the vehicle. Two types of road tests namely step steer test and double lane change test have been performed and data gathered from the tests were used as the benchmark of the model validation. The wheel steer angle data measured from the test in both step steer and double lane change tests were used as the inputs of the simulation model. Some of the vehicle behaviors to be validated in this works were yaw rate, lateral acceleration, body roll angle and tire slip angle responses. The results of model validation show that the trends between simulation results and experimental data are almost similar with acceptable error. The small difference in magnitude between simulation and experimental results is mainly due to the simplification/idealization in vehicle dynamics modeling and the difficulty of the driver to maintain a constant speed during maneuvering.

From the simulation results, it is clear that the performance of the proposed control structure is proven to outperform the performance of passive system in all the selected performance criteria. The need of additional roll moment rejection loop to the PID controller is also strongly justified. In general, it can be concluded that the proposed PID control with roll moment rejection loop for ARC system significantly enhances the maneuverability of the vehicle by reducing both roll rate and roll angle in the presence of the steering angle input from the driver. Improvement in body acceleration and body heave response indicate that the comfort level of the vehicle can also be improved drastically using the proposed control structure. Improvement in comfort level will avoid the driver from fatigue as well as reduce the possibility of the driver from losing control of the vehicle during maneuvering. Four units of pneumatic actuators have been installed in parallel with the existing passive suspensions into the instrumented experimental vehicle for the ARC system. A PC-based controller for ARC system using the proposed control structure was then implemented through experimental test on real vehicle situations namely step steer and double lane change tests to investigate the effectiveness of the controller in attenuating the effect of 
steering input from the driver. The experimental results show that the ARC system is able to reduce the unwanted motions of vehicle body namely body roll angle, body roll rate, body vertical acceleration and body vertical displacement significantly. It can also be concluded that better improvement on vehicle stability was obtained using the ARC system.

\section{Acknowledgement}

This work is supported by the Ministry of Higher Education (MoHE) of Malaysia through FRGS project entitled "Development of a Pneumatically Actuated Active Roll Control Suspension System" lead by Dr. Khisbullah Hudha at the Universiti Teknikal Malaysia Melaka. This financial support is gratefully acknowledged.

\section{References}

Ahmad, F., Hudha, K., Said, M. R. and Rivai, A. (2008). Development of Pneumatically Actuated Active Stabilizer Bar to Reduce Vehicle Dive. International Conference on Plant Equipment and Reliability (ICPER). March 27-28. Kuala Lumpur, Malaysia.

Ahmad, F., Hudha, K. and Jamaluddin, H. (2009a). Modeling Validation and Gain Scheduling PID Control fo Pneumatically Actuated Active Suspension System for Reducing Unwanted Vehicle Motion in Longitudinal Direction. International Journal of Vehicle Safety (IJVS). 4 (1): 38-45.

Ahmad, F., Hudha, K. and Harun, M. H. (2009b). Pneumatically Actuated Active Suspension System for Reducing Vehicle Dive and Squat. Jurnal Mekanikal UTM . (28): 85-114.

Araki, M. (2006). PID Control, in Unbehauen, H. (ed) Control Systems, Robotics and Automation - Vol. II , UNESCO: Encyclopedia of Life Support Systems

Ayat, M. L., Diop, S. and Fenaux, E. (2002a). Development of a Full Active Suspension System. Proceedings of a15 th Triennial World Congress of the International Federation of Automatic Control. July 21-26. Barcelona, Spain. Paper No. 2658.

Ayat, M. L., Diop, S. and Fenaux, E. (2002b). An Improved Active Suspension Yaw Rate Control. Proceedings of the American Control Conference. May 8-10. Anchorage, AK. 2: 863-868.

Ben-Dov, D. and Salcudean, S. E. (1995). A force-controlled pneumatic actuator. IEEE Transactions on Robotics and Automation. Vol.11, No.6, pp. 906-911.

Borrelli, F., Bemporad, A., Fodor, M. and Hrovat, D. (2006). An MPC/hybrid System Approach to Traction Control. IEEE Transactions on Control Systems Technology. 14(3): $541-552$.

Bustamante, J., Diong, B. and Wicker, R. (2000). System Identification and Control Design of an Alternative Fuel Engine for Hybrid Power Generation. Proceeding of the IEEE 35th Intersociety Energy Conversion Engineering Conference and Exhibit, 2000 (IECEC). July 24-28. Las Vegas, USA. Vol. 1, pp.329-339.

Cabrera, J. A., Ortiz, A., Castillo, J. J. and Simon, A. (2005). A Fuzzy Logic Control for Antilock Braking System Integrated in the IMMa Tire Test Bench. IEEE Transactions on Vehicular Technology. 54(6): 1937 - 1949. 
Corno, M., Tanelli, M., Savaresi, S. M., Fabbri, L. And Nardo, L. (2008). Electronic Throttle Control for Ride-by-Wire in Sport Motorcycles. Proceeding of the IEEE International Conference on Control Applications 2008 (CCA'2008). September 3-5. San Antonio, Taxes, USA. pp. 233-238.

Darling, J. and Ross-Martin, T. J. (1997). A Theoretical Investigation of a Prototype Active Roll Control System. Journal of Automobile Engineering. 211(1): 3-12.

Du, H. and Dong, G. (2007). Robust Active Roll Controller Design for Vehicles Considering Variable Speed and Actuator Delay. SAE Technical Paper Series. Paper No. 2007-010825 .

Falcone, P., Borrelli, F., Asgari, J., Tseng, H. E. and Hrovat, D. (2007). Predictive Active Steering Control for Autonomous Vehicle Systems. IEEE Transactions on Control Systems Technology. 15(3): 566 - 580.

Hanafi, D. (2010). PID Control Design for Semi-active Car Suspension Based on Model from Intelligent System Identification. Proceeding of the IEEE Second International Conference on Computer Engineering and Applications (ICCEA 2010). March 19-21. Bali Island, Indonesia. pp. 60-63.

Hashemi-Dehkordi, S. M., Mailah, M. and Abu-Bakar, A. R. (2008). A Robust Active Control Method To Reduce Brake Noise. Proceedings of the IEEE Conference on Robotics and Biometrics. February 22-25. Bangkok, Thailand. pp. 739-744.

Hudha, K., Jamaluddin, H. Samin, P. M. and Rahman, R. A. (2003). Semi Active Roll Control Suspension System on a New Modified Half Car Model. SAE Technical Paper Series. Paper No. 2003-01-2274

Ikenaga, S. A. (2000). Development of a Real Time Digital Controller: Application to Active Suspension Control of Ground Vehicles. Michigan University: PhD. Dissertation.

Kadir, Z. A., Hudha, K., Nasir, M. Z. M. and Said, M. R.(2008). Assessment of Tire Models for Vehicle Dynamics Analysis. Proceedings of the International Conference on Plant Equipment and Reliability. March 27-28. Kuala Lumpur, Malaysia.

Mammar, S. and Koenig, D. (2002). Vehicle Handling Improvement by Active Steering. Vehicle System Dynamics. 38(3): 211-242.

Marino, R., Scalzi, S., Orlando, G. and Netto, M. (2009). A Nested PID Steering Control for Lane Keeping in Vision Based Autonomous Vehicle. Proceeding of the IEEE American Control Conference Conference Hyatt Regency Riverfront. June 10-12. Saint Louis, Missouri, USA. pp. 2885-2890.

McCann, R. (2000). Variable Effort Steering for Vehicle Stability Enhancement Using an Electric Power Steering System. SAE Technical Paper Series. Paper No. 2000-01-0817.

Messina, A., Giannoccaro, N. I. and Gentile, A. (2005) .Experimenting and modelling the dynamics of pneumatic actuators controlled by the pulse width modulation (PWM) technique. Mechatronics. Vol.15, pp. 859-881.

Miege, A. and Cebon, D. (2002). Design and Implementation of an Active Roll Control System for Heavy Vehicles. Proceedings of the $6^{\text {th }}$ International Symposium on Advanced Vehicle Control (AVEC). September 9-13.Hisoshima, Japan.

Mingzhu, Z., Zhili, Z., Jinfa, X. and Zhiqiang, X. (2008). Modeling and Control Simulation for Farm Tractor with Hydro-Mechanical CVT. Proceeding of the IEEE International Conference on Automationand Logistics 2008 (ICAL 2008). September 1-3.Qingdao, China. pp. 908-913. 1. 
Mokhiamar, O. and Abe, M. (2002). Effect of Model Response on Model Following Type of Combined Lateral Force and Yaw Moment Control Performance for Active Vehicle Handling Safety. JSAE Review. 23: 473-480.

Morita, Y., Torii, K., Tsucida, N., Iwasaki, M., Ukai, H., Matsui, N., Hayashi, T., Ido, W. and Ishikawa, H. (2008). Improvement of Steering Feel of Electric Power Steering System with Variable Gear Transmission System Using Decoupling Control. Proceeding of the IEEE International Workshop on Advanced Motion Control 2008 (AMC2008). March 26-28. Trento, Italy. pp. 417-422,

Richer, E. and Hurmuzlu, Y. (2000). A high performance pneumatic force actuator system Part II -Nonlinear controller design. Journal of Dynamic Systems, Measurement and Control. pp.426-434.

Shoubo, L., Chenglin, L., Shanglou, C. and Lifang, W. (2009). Traction Control of Hybrid Electric Vehicle. Proceeding of the IEEE Vehicle Power and Propulsion Conference, 2009(VPPC'09). September 7-10. Dearbon, Michigan, USA. pp. 1535-1540.

Singh, T., Kesavadas, T., Mayne, R., Kim, J. J. and Roy, A. (2002). Design of Hardware/Algorithms for Enhancement of Driver-Vehicle Performance in Inclement Weather Conditions Using a Virtual Environment, SAE Paper No. 200201-0322.

Situm, Z., Kosic, D. and Essert, M. (2005). Nonlinear Mathematical Model of a Servo Pneumatic System. Proceedings of Nineth International Research/Expert Conference, Antalya, Turkey.

Smaoui, M., Brun, X. and Thomasset, D. (2006). A study on tracking position control of an electropneumatic system using backstepping design. Control Engineering Practice. Vol.14, No. 8, pp.923-933.

Sorniotti, A. and D'Alfio, N. (2007). Vehicle Dynamics Simulation to Develop an Active Roll Control System. SAE Technical Paper Series. Paper No. 2007-01-0828.

Sugisaka, M., Tanaka, H. and Hara, M. (2006). A Control Method of Accelerator of an Electric Vehicle. Proceedings of the IEEE International Joint Conference (SICEICASE,2006). October 18-21. Busan, Korea. pp 5300-5303.

Szostak, H. T., Allen, W. R. and Rosenthal, T. J. (1988). Analytical Modeling of Driver Response in Crash Avoidance Maneuvering Volume II: An Interactive Model for Driver/Vehicle Simulation. US Department of Transportation Report NHTSA DOT HS-807-271. April.

Takatsu, H., Itoh, T. and Araki, M. (1998). Future Needs for the Control Theory in Industries Report and Topics of the Control Technology Survey in Japanese Industry. Journal of Process Control. 8 (5-6): 369-374.

Tan, Y., Robotis, A. and Kanellakopoulos, I. (1999). Speed Control Experiment with an Automated Heavy Vehicle. Proceeding of the 1999 IEEE International Conference on Control Applications. August 22-27. Kohala Coast, Hawaii, USA. Vol. 2, pp.13531358.

Wang, J., Pu, J. and Moore, P. (1999). Accurate position control of servo pneumatic actuator systems: an application to food packaging. Control Engineering Practice. Vol.7, No. 7, pp. 699-706.

Wang, J. and Longoria, R. G. (2006). Coordinated Vehicle Dynamics Control with Control Distribution. Proceedings of the 2006 American Control Conference. June 14-16. Minneapolis, Minnesota, USA. 
Wang, Y., Kraska, M. and Ortmann, M. (2001). Dyanamic Modeling of a Variable Force and a Cluth for Hydraulic Control in Vehicle Transmission System. Proceeding of the IEEE 2001 American Control Conference. August 7. Arlington, Virginia, USA.Vol. 3, pp.1789-1793.

Wang, J., Wilson, D. A., Xu. W. and Crolla, D. A. (2005). Active Suspension Control to Improve Vehicle Ride and Steady State Handling. Proceedings of the 44th IEEE Conference on Decision and Control. December 12-15. Seville, Spain. 1982-1987.

Wei, L., Wei, L., Jia, Y. and Gang, J. L. (2010). Simulation of CVT Ratio Control Strategy of Engine Braking. Proceeding of the IEEE $2^{\text {nd }}$ International Asia Conference on Informatics in Control, Automation and Robotics (CAR). March 6-7. Wuhan, China. pp.166-169.

Williams, D. E. and Haddad, W. M. (1995). Nonlinear Control of Roll Moment Distribution to Influence Vehicle Yaw Characteristics. IEEE Transaction on Control System Technology. 3(1): 110-116.

Wu, X., Wang, X., Yu, T. and Xie, X. (2008). Control of Electronic Clutch During Vehicles Start. Proceeding of the IEEE Vehicle Power and Propulsion Conference, 2008 (VPPC'2008). September 3-5. Harbin, China. pp.1-5.

Xinpeng, T. and Duan, X. (2007). Simulation and Study of SUV Active Roll Control Based on Fuzzy PID. SAE Technical Paper Series. Paper No. 2007-01-3570.

$\mathrm{Xu}, \mathrm{N} ., \mathrm{Chen}, \mathrm{H} ., \mathrm{Hu}, \mathrm{Y}$. and Liu, H. (2007). The Integrated Control System in Automatic Transmission. Proceeding of the IEEE International Conference on Mechatronics and Automation. August 5-8. Harbin, China. pp. 1655-1659.

Ying, H., Fujun, Z., Fushui, L., Yunshun, G. and Yebao, S. (1999). Gasoline Engine Idle Speed Control System Development Based on PID Algorithm. Proceeding of the IEEE International Vehicle Electronic Conference 1999 (IVEC'99). September 6-9. Changcun, China. Vol. 1, pp.30-31.

Yan, Y. L., Guang, Q. Y. and Feng, L. (2008). Research on Control Strategy and Bench Test of Automobile Steer-by-Wire System. Proceeding of the IEEE Vehicle Power and Propulsion Conference (VPPC). September 3-5. Harbin, China. pp.1-6.

Yuanyuan, Z., Jianbo, S. and Guo, C. (2008). Research on the Modeling and Simulation of the Four-stroke Engine and it's Control. Proceeding of the IEEE $7^{\text {th }}$ International Conference on System Simulation and Scientific Computing,2008 (ICSC2008). October 10-12. Beijing, China. pp.1321-1324.

Zhang, D., Zheng, H., Sun, J., Wang, Q., Wen, Q., Yin, A. and Yang, Z. (1999). Simulation Study for Anti-lock Bracking system of a Light Bus. Proceeding of the IEEE International Vehicle Electronics Conference,1999(IVEC'99). September 6-9. Changcun, China. Vol. 1, pp.70-77.

Zhang, J. D., Qin, G. H., Xu, B,. Hu, H. S. and Chen, Z. X. (2010). Study on Automotive Air Conditioner Control System Based on Incremental-PID. Journal of Advanced Materials Research. Vol. 129-131, pp 17-22 


\section{Appendix}

Vehicle Model Parameters:

\begin{tabular}{|c|c|c|c|c|}
\hline $\begin{array}{c}M \\
(\mathrm{~kg}) \\
\end{array}$ & $\begin{array}{l}\text { lf } \\
(\mathrm{m})\end{array}$ & $\begin{array}{c}\text { lr } \\
(\mathrm{m})\end{array}$ & $\begin{array}{c}w \\
(\mathrm{~m})\end{array}$ & $\begin{array}{l}\text { hcg } \\
(\mathrm{m})\end{array}$ \\
\hline 920 & 1.34 & 1.04 & 1.34 & 0.5 \\
\hline $\begin{array}{c}I z \\
\left(\mathrm{~kg} / \mathrm{m}^{2}\right)\end{array}$ & $\begin{array}{c}J w \\
\left(\mathrm{~kg} / \mathrm{m}^{2}\right)\end{array}$ & $\begin{array}{c}\text { Ir } \\
\left(\mathrm{kg} / \mathrm{m}^{2}\right)\end{array}$ & $\begin{array}{c}\text { Csfl, Csfr, } \\
\text { Csrl, Csrr } \\
\left(\mathrm{N} / \mathrm{msec}^{-1}\right)\end{array}$ & $\begin{array}{c}\text { Ksfl, Ksfr, } \\
\text { Ksrl, Ksrr } \\
(\mathrm{N} / \mathrm{m})\end{array}$ \\
\hline 3190 & 1.2825 & 400 & 750 & 30000 \\
\hline
\end{tabular}

Tire Parameters:

\begin{tabular}{|c|c|}
\hline Parameter & RWD radial \\
\hline Tire Type & 155SR13 \\
\hline$T w$ & 6 \\
\hline$T p$ & 24 \\
\hline$F Z T$ & 810 \\
\hline$C 1$ & 1.0 \\
\hline$C 2$ & 0.34 \\
\hline C3 & 0.57 \\
\hline$C 4$ & 0.32 \\
\hline A0 & 914.02 \\
\hline$A 1$ & 12.9 \\
\hline$A 2$ & 2028.24 \\
\hline Ka & 0.05 \\
\hline$C S / F Z$ & 18.7 \\
\hline$\mu o$ & 0.85 \\
\hline
\end{tabular}

Controller Parameters:

\begin{tabular}{|l|c|c|c|}
\hline \multicolumn{1}{|c|}{ PID } & $\boldsymbol{K} \boldsymbol{p}$ & $\boldsymbol{K} \boldsymbol{i}$ & $\boldsymbol{K} \boldsymbol{d}$ \\
\hline Body Heave Control & 30000 & 0.00033 & 22500 \\
\hline Body Roll Control & 7500 & 0.00003 & 3000 \\
\hline
\end{tabular}


www.intechopen.com 


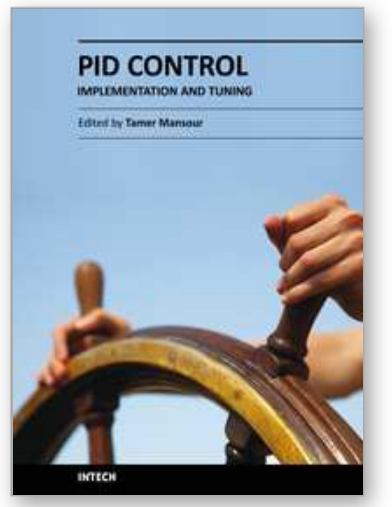

\author{
PID Control, Implementation and Tuning \\ Edited by Dr. Tamer Mansour
}

ISBN 978-953-307-166-4

Hard cover, 238 pages

Publisher InTech

Published online 19, April, 2011

Published in print edition April, 2011

The PID controller is considered the most widely used controller. It has numerous applications varying from industrial to home appliances. This book is an outcome of contributions and inspirations from many researchers in the field of PID control. The book consists of two parts; the first is related to the implementation of PID control in various applications whilst the second part concentrates on the tuning of PID control to get best performance. We hope that this book can be a valuable aid for new research in the field of PID control in addition to stimulating the research in the area of PID control toward better utilization in our life.

\title{
How to reference
}

In order to correctly reference this scholarly work, feel free to copy and paste the following:

Khisbullah Hudha, Fauzi Ahmad, Zulkiffli Abd. Kadir and Hishamuddin Jamaluddin (2011). Pid Controller with Roll Moment Rejection for Pneumatically Actuated Active Roll Control (ARC) Suspension System, PID Control, Implementation and Tuning, Dr. Tamer Mansour (Ed.), ISBN: 978-953-307-166-4, InTech, Available from: http://www.intechopen.com/books/pid-control-implementation-and-tuning/pid-controller-with-roll-momentrejection-for-pneumatically-actuated-active-roll-control-arc-suspens

\section{INTECH}

open science | open minds

\section{InTech Europe}

University Campus STeP Ri Slavka Krautzeka 83/A 51000 Rijeka, Croatia Phone: +385 (51) 770447 Fax: +385 (51) 686166 www.intechopen.com

\section{InTech China}

Unit 405, Office Block, Hotel Equatorial Shanghai No.65, Yan An Road (West), Shanghai, 200040, China 中国上海市延安西路65号上海国际贵都大饭店办公楼405单元 Phone: +86-21-62489820

Fax: +86-21-62489821 
(C) 2011 The Author(s). Licensee IntechOpen. This chapter is distributed under the terms of the Creative Commons Attribution-NonCommercialShareAlike-3.0 License, which permits use, distribution and reproduction for non-commercial purposes, provided the original is properly cited and derivative works building on this content are distributed under the same license. 